\title{
A model of mercury cycling and isotopic fractionation in the ocean
}

\author{
David E. Archer ${ }^{1}$ and Joel D. Blum ${ }^{2}$ \\ ${ }^{1}$ Department of the Geophysical Sciences, University of Chicago, Chicago, 60637, USA \\ ${ }^{2}$ Department of Earth and Environmental Sciences, University of Michigan, Ann Arbor, Michigan, 48109, USA
}

Correspondence: David E. Archer (d-archer@uchicago.edu)

Received: 5 March 2018 - Discussion started: 7 March 2018

Revised: 21 August 2018 - Accepted: 21 September 2018 - Published: 26 October 2018

\begin{abstract}
Mercury speciation and isotopic fractionation processes have been incorporated into the HAMOCC offline ocean tracer advection code. The model is fast enough to allow a wide exploration of the sensitivity of the $\mathrm{Hg}$ cycle in the oceans, and of factors controlling human exposure to monomethyl-Hg through the consumption of fish. Vertical particle transport of $\mathrm{Hg}$ appears to play a discernable role in setting present-day $\mathrm{Hg}$ distributions, which we surmise by the fact that in simulations without particle transport, the high present-day $\mathrm{Hg}$ deposition rate leads to an $\mathrm{Hg}$ maximum at the sea surface, rather than a subsurface maximum as observed. $\mathrm{Hg}$ particle transport has a relatively small impact on anthropogenic Hg uptake, but it sequesters $\mathrm{Hg}$ deeper in the water column, so that excess $\mathrm{Hg}$ is retained in the model ocean for a longer period of time after anthropogenic $\mathrm{Hg}$ deposition is stopped. Among 10 rate constants in the model, steady-state $\mathrm{Hg}$ concentrations are most sensitive to reactions that are sources or sinks of $\operatorname{Hg}(0)$, the evasion of which to the atmosphere is the dominant sink term in the surface ocean. Isotopic fractionations in the interconversion reactions are most strongly expressed, in the isotopic signatures of dissolved $\mathrm{Hg}$, in reactions that involve the dominant dissolved species, $\mathrm{Hg}$ (II), including mass independent fractionation during $\mathrm{Hg}$ photoreduction. The $\Delta^{199} \mathrm{Hg}$ of $\mathrm{MMHg}$ in the model, subject to photoreduction fractionation, reproduces the $\Delta^{199} \mathrm{Hg}$ of fish in the upper $1000 \mathrm{~m}$ of the ocean, while the impact of anthropogenic $\mathrm{Hg}$ deposition on $\mathrm{Hg}$ isotope ratios is essentially negligible.
\end{abstract}

\section{Background}

The element mercury $(\mathrm{Hg})$ is a powerful neurotoxin (Clarkson and Magos, 2006). When transformed to methyl mercury $(\mathrm{MeHg})$ it is known to amplify its toxicity by bioaccumulating up the food chain. The main human exposure to $\mathrm{MeHg}$ is via consumption of high trophic level seafood (Chen et al., 2016; Schartup et al., 2018). Humans have been mining and mobilizing $\mathrm{Hg}$ into the Earth surface environment for hundreds of years, as a by-product of coal combustion, for its use in gold mining, and in products such as electronics and light bulbs (Amos et al., 2013; Driscoll et al., 2013; Krabbenhoft and Sunderland, 2013; Lamborg et al., 2014; Obrist et al., 2018; Streets et al., 2017; Mason et al., 2012). The Hg load in the surface ocean has increased by a factor of 3-5 since the industrial revolution; this represents a massive human impact on the global $\mathrm{Hg}$ cycle (Streets et al., 2017).

$\mathrm{Hg}$ can be extremely mobile in the environment, with gaseous forms in the atmosphere, and with particle-reactive forms allowing it to travel through soils and rivers and into the oceans (Fitzgerald et al., 2007). Hg(II) has a high affinity for complexing with (or adsorbing to) sulfur-rich ligands in organic matter (Schartup et al., 2015) and this leads to $\mathrm{Hg}$ accumulation with organic carbon in soils (Amos et al., 2013; Smith-Downey et al., 2010; Biswas et al., 2008) and sediments (Hollweg et al., 2010). The high mobility of $\mathrm{Hg}$ implies that the amount of $\mathrm{Hg}$ in Earth surface reservoirs is transient, even in the steady-state prehuman $\mathrm{Hg}$ cycle (Amos et al., 2013), and that $\mathrm{Hg}$ can be potentially mobilized by human impacts such as the thawing of Arctic permafrost (Schuster et al., 2018; Obrist et al., 2017) or enhanced wildfire activity (Turetsky et al., 2006). 
The $\mathrm{Hg}$ cycle is analogous to the carbon cycle, in which fossil fuel extracted from the solid Earth is released to a fast surface system consisting of soils and oceans in communication via the atmosphere. In both cases, the long-term sink for the perturbation is burial in sediments of the ocean. Because these burial fluxes are relatively slow, it will take a long time for these perturbations to subside: thousands of years for the $\mathrm{Hg}$ cycle (Amos et al., 2013), and hundreds of thousands of years for the carbon cycle (Archer et al., 2009). Other forms of environmental degradation that will persist for thousands of years include actinide radioactive waste, and some anthropogenic gases such as sulfur hexafluoride (Ray et al., 2017).

It is extremely challenging to predict the future of human exposure to $\mathrm{Hg}$, because the $\mathrm{Hg}$ cycle is so complex (Blum, 2013). One challenge has been to characterize the quantitative role of $\mathrm{Hg}$ adsorbed onto sinking particles in the ocean (Lamborg et al., 2016), which will constrain how deeply anthropogenic $\mathrm{Hg}$ may have penetrated into the ocean (Lamborg et al., 2014; Munson et al., 2015; Zhang et al., 2014b). Another is to understand the factors that control the production of $\mathrm{MeHg}$, which is the bio-accumulating form but which comprises only a small fraction of the $\mathrm{Hg}$ in the ocean (Schartup et al., 2013, 2015; Ortiz et al., 2015; Lehnherr et al., 2011; Lehnherr, 2014; Jonsson et al., 2016; Chakraborty et al., 2016; Blum et al., 2013).

Stable isotopes provide a powerful tool for determining the origins (Kwon et al., 2014; Li et al., 2014; Sherman et al., 2013, 2015; Balogh et al., 2015; Demers et al., 2015; Donovan et al., 2013, 2014; Gehrke et al., 2011; Sun et al., 2016; Tsui et al., 2014; Sonke, 2010; Yin et al., 2013) and transformations (Kwon et al., 2013, 2014; Rodriguez-Gonzalez et al., 2009; Chandan et al., 2015; Yang and Sturgeon, 2009; Foucher, 2013; Jiskra, 2012) of $\mathrm{Hg}$ in the natural environment. $\mathrm{Hg}$ has seven stable isotopes, with six at high abundance $(>1 \%)$. Most chemical processes fractionate the various isotopes progressively according to their masses (massdependent fractionation; MDF). If all fractionation processes were strictly mass dependent, measurements of the proportions of more than two isotopes would be redundant information. However, $\mathrm{Hg}$ is susceptible to light-stimulated reactions, which include oxidation of $\mathrm{Hg}(0)$ and reduction of $\mathrm{Hg}(\mathrm{II})$ and $\mathrm{MeHg}$. These photochemical reactions exhibit MDF and mass independent fractionation (MIF), which distinguishes between isotopes beyond their mass differences (Blum et al., 2014; Bergquist and Blum, 2009). Odd mass number mass independent fractionations, or "odd-MIF", are produced by two mechanisms. Large magnitude effects $(>\sim$ $0.4 \%$ ) are seen in kinetic short-lived radical pair reactions and are believed to be caused by the magnetic isotope effect (Buchachenko, 2001; Bergquist and Blum, 2009). Smaller magnitude odd-MIF can also be produced during dark equilibrium reduction and oxidation reactions by the nuclear volume effect (Schauble, 2007; Zheng and Hintelmann, 2010). "Even-MIF" has been observed in $\mathrm{Hg}$ in the atmosphere (Gratz et al., 2010) and deposited from atmospheric sources
(Strok et al., 2015; Zheng et al., 2016) and is believed to occur in the tropopause, but the specific mechanism is not known (Chen et al., 2016). Mass independent fractionation provides multiple degrees of freedom, allowing measurements of the proportions of all the isotopes to carry much more information than would be possible if only MDF occurred.

We have incorporated a model of the chemical transformations and isotopic fractionations of $\mathrm{Hg}$ in the ocean into the HAMOCC offline ocean passive tracer advection model (Maier-Reimer and Hasselmann, 1987). The flow field is taken from the large-scale geostrophic (LSG) dynamics model, which is also extremely fast and efficient for 3-D ocean flow (Maier-Reimer, 1993). The LSG physical model takes a time step of a month by eliminating non-geostrophic parts of the circulation that would be violated by this extremely long time step. The HAMOCC tracer advection model takes an annual average flow field from 12 monthly time steps of the LSG model and uses it to advect tracers through the ocean. While the tracers are flowing, they are exchanged with the atmospheric gases (in the case of $\mathrm{CO}_{2}$ and $\mathrm{O}_{2}$ ) and with biota (such as $\mathrm{CO}_{2}, \mathrm{O}_{2}$, alkalinity, and nutrients).

The distribution of $\mathrm{Hg}$ in the ocean today is the product of a presumably steady-state natural $\mathrm{Hg}$ cycle, which takes thousands of years to achieve in the model due to the ocean turnover time, followed by a global human perturbation, which began in about 1850 (and which could persist for thousands of years into the future). HAMOCC is believed to still be the fastest offline 3-D ocean tracer advection code in existence and is ideal for studying the sensitivity of the ocean $\mathrm{Hg}$ cycle on these long timescales. This paper is also the first attempt in our knowledge to simulate the isotopic fractionation processes of $\mathrm{Hg}$ in the ocean, which take thousands of years to express themselves globally.

\section{Modeling methods}

\subsection{Mercury geochemistry solvers}

The geochemical cycling of $\mathrm{Hg}$ in the ocean in $\mathrm{Hg}$ HAMOCC is similar in conception to previous models (Fig. 1). $\mathrm{Hg}$ interconverts between $\mathrm{Hg}(\mathrm{II}), \mathrm{Hg}(0)$, monomethyl-Hg (MMHg), dimethyl-Hg (DMHg), and $\mathrm{Hg}$ adsorbed to sinking particles $(\mathrm{Hg}-\mathrm{P})$. The rates of the biological reactions are correlated to each other and to the overall rate of metabolic activity in the Semeniuk and Dastoor (2017) model and in our model, with typical values as shown in Fig. 1. The rate constant for MMHg production from $\mathrm{Hg}(\mathrm{II})$ is proportional to the rate of particulate organic carbon (POC) degradation, which is derived from the attenuation with depth of the sinking POC flux in HAMOCC (expressed as a volumetric rate of POC degradation). 


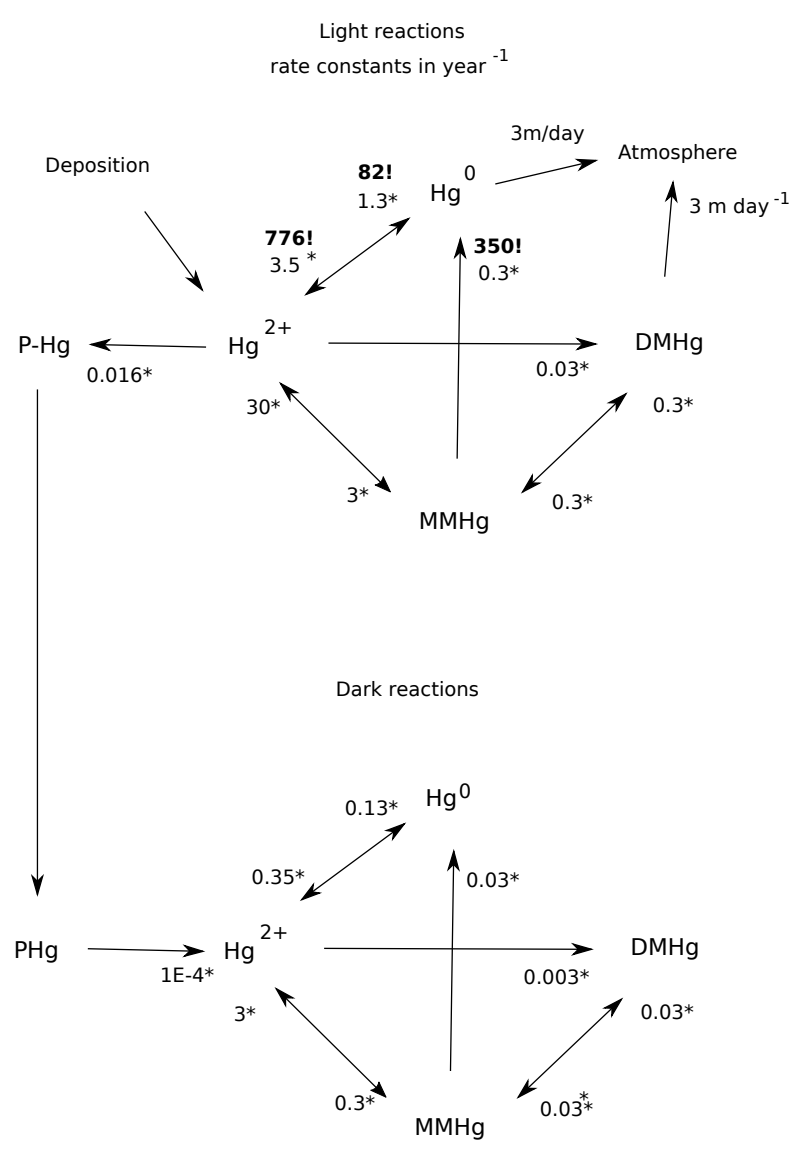

Figure 1. Schematic of the reaction web for $\mathrm{Hg}$ speciation in the model. Starred numbers by the arrows show typical values for biologically mediated rate constants, measured as per year $\left(\mathrm{yr}^{-1}\right)$. Photochemical rate constants are denoted by bold text and exclamation marks (!). Gas evasion rate constants are based on an oceanaverage piston velocity of $3 \mathrm{~m} \mathrm{day}^{-1}$ (Broecker and Peng, 1974). Biological rate constants are fit to Semeniuk and Dastoor (2017) and Zhang et al. (2014a), based on first-order degradation kinetics for POC, resulting in a scaling $k_{\text {bio }}=10^{-6}[\mathrm{POC}]\left(\mathrm{mol} \mathrm{L}^{-1}\right)$. Photochemical $\mathrm{MMHg}$ degradation rate constant is from Bergquist and Blum (2007). $\mathrm{Hg}(\mathrm{II})$ photoreduction and $\mathrm{Hg}(0)$ photooxidation rate constants are fits to the global budget from Soerensen et al. (2010).

Other $\mathrm{Hg}$ transformation reactions are provoked by light (Blum et al., 2014; Bergquist and Blum, 2007) and only take place in the surface ocean. The rate of photochemical reactions in $\mathrm{Hg}$-HAMOCC is about a factor of 2 higher in low versus high latitudes, using the latitudinal function that governs export production rates in HAMOCC. The photochemical reaction rates are attenuated with water depth, using an $e$-folding depth scale of $20 \mathrm{~m}$. The wavelength dependence of photochemical reactions and fractionations is complex (Rose et al., 2015), and the attenuation depth of the light varies with frequency, so the $20 \mathrm{~m}$ depth scale is only an approximation. The actual mechanisms for DMHg production and degrada- tion are still uncertain, so the model formulation can be regarded as something of placeholder for the time being. The rates of gas evasion of $\mathrm{Hg}(0)$ and $\mathrm{DMHg}$ are taken to be proportional to the concentrations of the species. The $\mathrm{Hg}$ cycle in the surface ocean is driven by deposition influx of $\mathrm{Hg}(\mathrm{II})$ and gas invasion of $\mathrm{Hg}(0)$, which are applied at uniform rates around the world.

All of the rate constants in Hg-HAMOCC are first-order, which is to say that the chemical rates are determined by multiplying the rate constant by a single species concentration to the first power. Rates of conversion between these species are generally fast, some much faster than the 1-year time step of the tracer code. For this reason, solvers were written to find steady-state distributions of the $\mathrm{Hg}$ species. Because the $\mathrm{Hg}$ system is strongly driven at the sea surface by air-sea fluxes, a separate solver system was developed for surface grid points than the one applied to subsurface grid points.

Export of sinking Hg-P is done separately from the speciation calculations in subsurface waters, but simultaneously with the speciation calculations in the surface ocean. $\mathrm{Hg}$ advection by ocean circulation is also done in an independent step from the chemistry and particle components. Since the $\mathrm{Hg}$ speciation is imposed to be at equilibrium by the speciation solvers, there is no need to carry speciation information through the advective system, which only needs to carry around a single tracer for the total $\mathrm{Hg}$ concentration. To treat the isotopic systematics of the $\mathrm{Hg}$ cycle, we added three additional advected $\mathrm{Hg}$ tracers, identical to the first but with slightly altered source fluxes or rate constants, in order to simulate variations in the relative abundances of isotopes ${ }^{199} \mathrm{Hg},{ }^{200} \mathrm{Hg}$, and ${ }^{202} \mathrm{Hg}$ relative to ${ }^{198} \mathrm{Hg}$.

\subsubsection{Surface ocean chemistry solver}

For the surface ocean, the distribution of $\mathrm{Hg}$ among the dissolved species is determined by a balance of $\mathrm{Hg}$ fluxes through the system: rain input of $\mathrm{Hg}(\mathrm{II})$ and $\mathrm{Hg}(0)$, and removal by $\mathrm{Hg}(\mathrm{II})$ scavenging on sinking particles and degassing as $\mathrm{Hg}(0)$ and DMHg. Concentration-dependent reaction rates in the model are all assumed to be first-order, i.e., linear in $\mathrm{Hg}$ concentration. This includes loss by gas evasion, which should be linear in $\mathrm{Hg}$ concentration in the piston velocity model, and loss of bound $\mathrm{Hg}$ on sinking particles, which is linear with $[\mathrm{Hg}(\mathrm{II})]$ in the adsorption model. The solver finds values for the $\mathrm{Hg}$ species concentrations at which the incoming and loss fluxes balance. The equations are as follows:

$$
\begin{gathered}
{\left[\begin{array}{cccc}
-k_{20}-k_{2 \mathrm{M}}-k_{2 \mathrm{D}}-S & k_{02} & k_{\mathrm{M} 2} & 0 \\
k_{20} & -k_{\mathrm{evn}}-k_{02} & k_{\mathrm{M} 0} & 0 \\
k_{2 \mathrm{M}} & 0 & -k_{\mathrm{M} 2}-k_{\mathrm{M} 0}-k_{\mathrm{MD}} & k_{\mathrm{DM}} \\
k_{2 \mathrm{D}} & 0 & k_{\mathrm{MD}} & -k_{\mathrm{evn} .}-k_{\mathrm{DM}}
\end{array}\right]} \\
{\left[\begin{array}{c}
{\left[\mathrm{Hg}^{2+}\right]} \\
{\left[\mathrm{Hg}^{0}\right]} \\
{[\mathrm{MMHg}]} \\
{[\mathrm{DMHg}]}
\end{array}\right]=\left[\begin{array}{c}
-\mathrm{Dep}_{\mathrm{Hg}^{2+}} \\
0 \\
0 \\
-\mathrm{Dep}_{\mathrm{Hg}^{0}}
\end{array}\right],}
\end{gathered}
$$




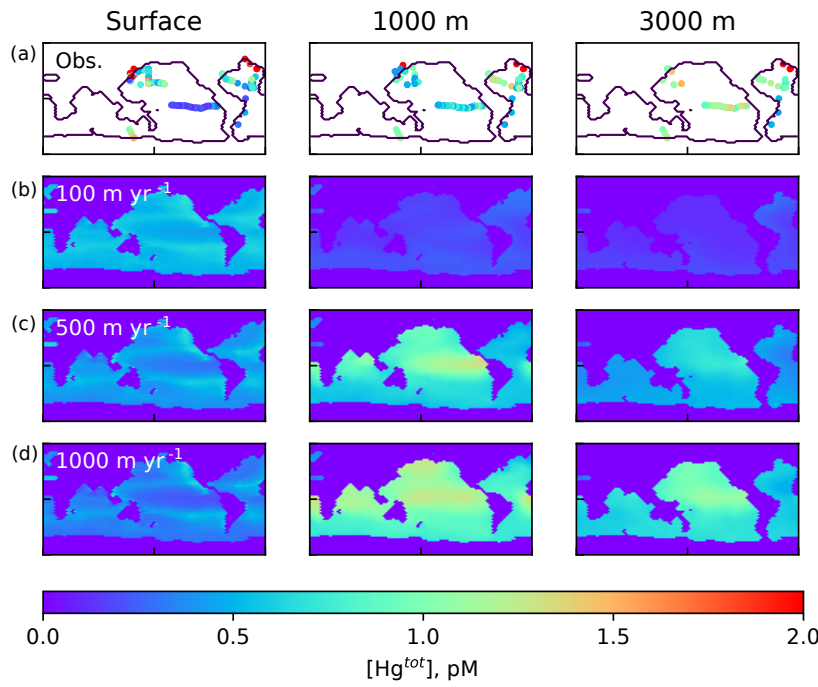

Figure 2. Comparison of $\mathrm{Hg}($ tot $)$ concentrations in $\mathrm{pM}$ from the model with data in the top row, from Laurier et al. (2004), Bowman et al. (2015), Bowman et al. (2016), Cossa et al. (2004), Cossa et al. (2011), Hammerschmidt and Bowman (2012), Lamborg et al. (2012), Mason et al. (2001), and Mason et al. (1998), at approximately the depths in the ocean given at the top. The lower three rows are present-day (year 2010) model results using different values of the particulate-bound $\mathrm{Hg}$ sinking velocity as indicated by the labels on the left, with $500 \mathrm{~m} \mathrm{yr}^{-1}$ as the base case.

where $k$ denotes a first-order rate constant, subscripts denote reactant and then product where $2=\mathrm{Hg}(\mathrm{II}), 0=\mathrm{Hg}(0), \mathrm{D}=$ $\mathrm{DMHg}$, and $\mathrm{M}=\mathrm{MMHg}$. The "Dep" terms on the right-hand side denote deposition from the atmosphere at fixed imposed rates. $S$ is a rate constant for $\mathrm{Hg}(\mathrm{II})$ sinking on particles,

$S=\left(1-\frac{1}{k_{\mathrm{b}}[\mathrm{POC}]+1}\right) \frac{R}{\mathrm{~d} z}$,

comprised of the POC concentration, the scavenging constant, and an imposed POC sinking velocity $R$. The diagonal terms in the first matrix represent sinks of the chemical species listed in the second matrix, when those sinks are calculated as the rate constants in the diagonal multiplied by the species concentration (which is solved for). The positive off-diagonal terms in the first matrix represent sources of species, which are calculated as rate constants times the concentration of the origin species. This linear algebraic calculation solves for the steady-state concentrations of the four $\mathrm{Hg}$ species without iteration (in contrast to an analogous solver in HAMOCC for $\mathrm{CO}_{2}$ system chemistry).

\subsubsection{Subsurface ocean chemistry solver}

The Hg cycle in the deep ocean differs from that of the surface in that fluxes of $\mathrm{Hg}$ into and out of the system (by desorption of $\mathrm{Hg}(\mathrm{II})$ from particles) are slow relative to the rates
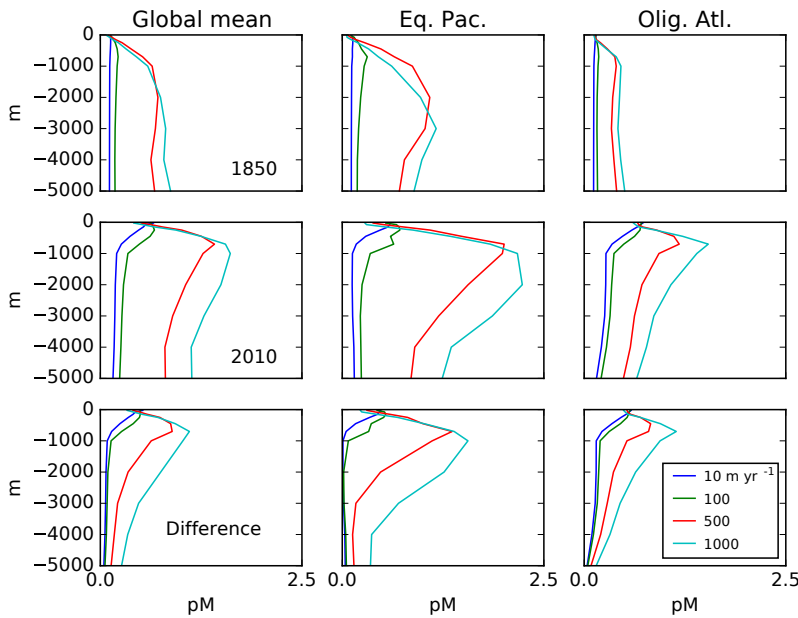

Figure 3. Depth profiles (in meters) of the total $\mathrm{Hg}$ concentration in the model: global mean and from locations shown in Fig. 4, showing preanthropogenic (1850), present-day (2010), and the difference between the two, for different values of the particulate-bound $\mathrm{Hg}$ flux in meters per year $\left(\mathrm{m} \mathrm{yr}^{-1}\right.$; the base case is $\left.500 \mathrm{~m} \mathrm{yr}^{-1}\right)$.

of interconversion between the $\mathrm{Hg}$ species. Because all of the rate constants are first-order, the relative proportions of the species are independent of the total $\mathrm{Hg}$ concentration. The solver finds steady-state values of all species relative to that of $\mathrm{Hg}(\mathrm{II})$, then scales everything to fit the total $\mathrm{Hg}$ concentration as produced by the advection routine. The equations are as follows:

$$
\begin{gathered}
{\left[\begin{array}{ccc}
-k_{02} & k_{\mathrm{M} 2} & 0 \\
0 & -k_{\mathrm{M} 0}-k_{\mathrm{M} 2}-k_{\mathrm{MD}} & k_{\mathrm{DM}} \\
0 & k_{\mathrm{MD}} & -k_{\mathrm{DM}}
\end{array}\right]} \\
\cdot\left[\begin{array}{c}
{\left[\mathrm{Hg}^{0}\right]} \\
{[\mathrm{MMHg}]} \\
{[\mathrm{DMHg}]}
\end{array}\right]=\left[\begin{array}{c}
-1 \mathrm{pM} \times k_{20} \\
-1 \mathrm{pM} \times k_{2 \mathrm{M}} \\
-1 \mathrm{pM} \times k_{2 \mathrm{D}}
\end{array}\right],
\end{gathered}
$$

where a concentration of $1 \mathrm{pM}$ is assumed for [Hg(II)], in order to work out the relative proportions of the other species. After the proportions of all the species concentrations are worked out, they are scaled to match the total $\mathrm{Hg}$ concentration as it is slowly changed by advection and desorption from POC. Maps of $\mathrm{Hg}$ total concentration are compared with measurements in Fig. 2, and profiles of the $\mathrm{Hg}$ species are shown in Fig. 3. In addition to the global mean, profiles from the highly productive equatorial Pacific to the oligotrophic Atlantic are shown to span the range of variability in the model.

\subsection{Hg adsorption and transport on particles}

$\mathrm{Hg}$ has a strong chemical affinity for organic matter, in particular for organic sulfur ligands. This chemistry leads $\mathrm{Hg}$ to adsorb onto organic matter in the ocean, leading to a vertical sinking flux of adsorbed $\mathrm{Hg}$ on particles (Lamborg et 


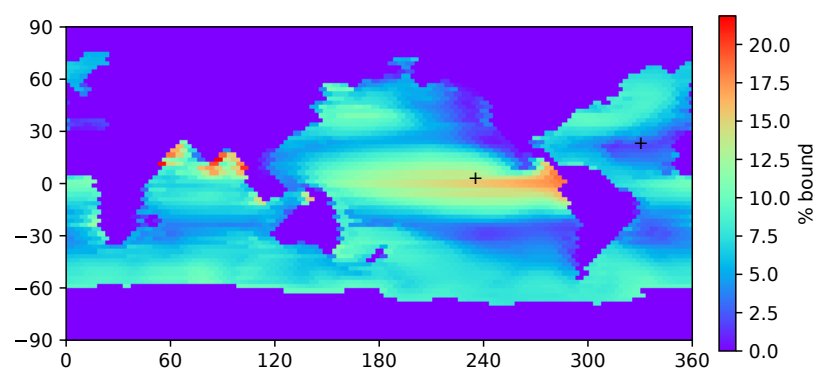

Figure 4. A map of the bound fraction of $\mathrm{Hg}$ (II) (relative to bound + unbound), at the sea surface, when the $K_{\mathrm{d}}$ value is $2 \times 10^{6}$. Higher POC concentrations in productive regions lead to higher bound fractions of the $\mathrm{Hg}(\mathrm{II})$. Plus signs indicate the locations of profiles in Figs. 3, 8, 12, 14, and 15.

al., 2016). Characterizing this flux is complicated by the fact that sinking particles compete for $\mathrm{Hg}$ with suspended and dissolved organic carbon (Han et al., 2006; Fitzgerald et al., 2007).

The biological pump in HAMOCC is represented as an instantaneous vertical redistribution of nutrients and other associated biological elements, without ever resolving them into particles or tracking their sinking. We constructed a hypothetical POC profile from this functioning of HAMOCC by choosing a POC sinking velocity that would transform the export production from the euphotic zone in HAMOCC into surface POC concentrations that are close to the observed mean concentration of about $5 \mu \mathrm{M}$. This sinking velocity of $500 \mathrm{~m}$ per year is much slower than the $100 \mathrm{~m}$ per day inferred sinking velocities of the particles that carry the bulk of the material caught in sediment traps, but it is similar to that used by other recent estimates (Semeniuk and Dastoor, 2017; Lamborg et al., 2016), and comparable to the result of modeling thorium on particles (Anderson et al., 2016), which (similarly to $\mathrm{Hg}$ ) binds to both suspended and sinking particles.

Because POC in the real ocean varies in size from dissolved to fast-sinking, the imposition of a single velocity in the model formulation, to be applied to the entire adsorbed $\mathrm{Hg}$ pool, is an oversimplification of reality, and the velocity required for the best fit is not a simple thing that can be measured directly in the real ocean. The sensitivity of the model to the sinking velocity is shown in Fig. 4. With an increase in sinking velocity, the "biological pump" for $\mathrm{Hg}$ becomes stronger, increasing the concentration in the deep ocean. The scavenging lifetime of $\mathrm{Hg}$ decreases as the sinking flux increases with increasing sinking velocity. When the $\mathrm{Hg}$ sinking velocity is set to $500 \mathrm{~m} \mathrm{yr}^{-1}$ (the same velocity as is used to transform the POC flux into a POC concentration), the global $\mathrm{Hg}$ sinking rate is similar to the result of Semeniuk and Dastoor (2017) (Fig. 5). However, sinking fluxes of $\mathrm{Hg}$ in the mid-water column are about a factor of 3 lower than equatorial and North Pacific sediment trap fluxes from Mun-
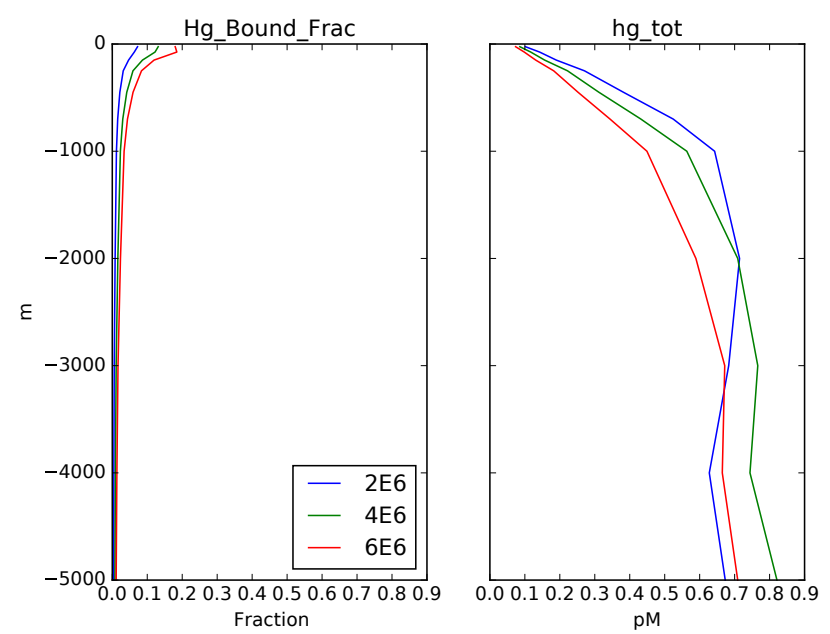

Figure 5. Depth profiles (in meters) of the bound fraction of $\mathrm{Hg}$ (II) from the same locations as in Fig. 3, as a function of the $K_{\mathrm{d}}$ value, preanthropogenic steady state (1850). A value of $2 \times 10^{6} \mathrm{~L} \mathrm{~kg}^{-1}$ POC (blue lines) is used in the rest of the model simulations.

son et al. (2015), so the models could be under-predicting the real particle fluxes if the Munson et al. (2015) data are globally representative. The turnover time of dissolved $\mathrm{Hg}$, with respect to transiting through the water column on sinking particles, depends on the sinking velocity, as shown in Fig. 4. Values approaching 1000 years in the deep ocean have been reported in other models (Semeniuk and Dastoor, 2017; Zhang et al., 2014a) and imply that circulation plays a major role in determining deep ocean $\mathrm{Hg}$ concentrations.

A second degree of freedom in the system of sinking $\mathrm{Hg}$ on particles is the adsorption constant $K_{\mathrm{d}}$, defined such that

$[\mathrm{Hg}-\mathrm{P}] /[\mathrm{Hg}(\mathrm{II})]=K_{\mathrm{d}}[\mathrm{POC}]$.

Semeniuk and Dastoor (2017) and Zhang et al. (2014b) used a value of $2 \times 10^{5}$, in units of liters per kilogram $\left(\mathrm{L} \mathrm{kg}^{-1}\right.$; requiring POC to be in kilograms per liter, $\mathrm{kg} \mathrm{L}^{-1}$ ), but included a factor of 10 correction for the fraction of particulate material in the ocean that is organic carbon (" $f_{\text {oc }}$ "), resulting in an effective $K_{\mathrm{d}}$ of $2 \times 10^{6}$. Lamborg et al. (2016) derived a value of about $4 \times 10^{6}$, which they claim to be a factor of 20 higher than the value used in the models, but after the $f_{\text {oc }}$ correction in the models the values only differ by a factor of 2 . The data from Bowman et al. (2015), analyzed by Lamborg et al. (2016), showed that about $5 \%$ of the $\mathrm{Hg}$ (II) in surface waters is bound to sinking particles, similar to the results from the models (Semeniuk and Dastoor, 2017). A map of the bound fraction in surface waters from our model is shown in Fig. 6, showing more particulate $\mathrm{Hg}$ in high-production (high POC) regions such as the equatorial Pacific. The sensitivity of the model to the value of $K_{\mathrm{d}}$ is shown in Fig. 4, with results similar to those for sinking velocity. The calculated lifetime of dissolved $\mathrm{Hg}$ in the water column, relative to removal by adsorption to sinking parti- 

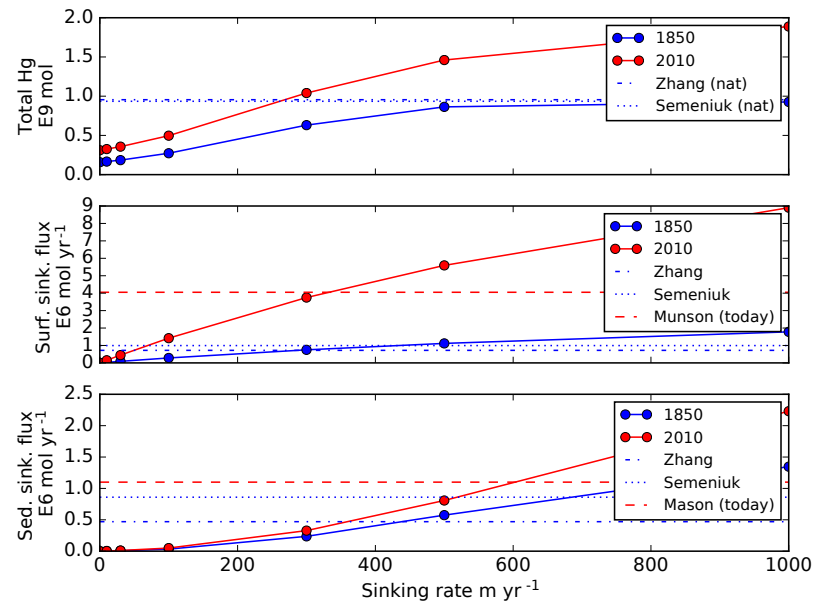

Figure 6. Global model fluxes as a function of $\mathrm{Hg}(\mathrm{II})$ sinking velocity imposed in the model. Colors represent preanthropogenic and present-day results from our model. For comparison broken lines are model results from Zhang et al. (2014a) and Semeniuk and Dastoor (2017), sediment trap data from Mason et al. (2012), $17^{\circ} \mathrm{N}$ latitude in the Pacific and $60 \mathrm{~m}$ water depth, extrapolated globally. A default value of $500 \mathrm{~m} \mathrm{yr}^{-1}$ is the base case for the rest of the simulations in this paper.

cles, is shown in Fig. 7. The figure is intended for comparison with results of other models, and to show that the $\mathrm{Hg}$ cycle in the ocean is close to a crossover point between dominance by fluid advection vs. sinking particles.

\subsection{Isotopic fractionation}

Mercury isotope fractionations associated with any of the processes in the $\mathrm{Hg}$ cycle are treated in the model as kinetic effects: slight perturbations in the rates of chemical transformations between the isotopes (rather than fractionation of the equilibrium state). This allows Hg-HAMOCC to impose fractionation effects onto the kinetic expressions in the solvers for surface and subsurface $\mathrm{Hg}$ speciation. The altered kinetic rate constants are applied to alternative total $\mathrm{Hg}$ concentration fields representing the isotopes ${ }^{199} \mathrm{Hg},{ }^{200} \mathrm{Hg}$, and ${ }^{202} \mathrm{Hg}$ relative to a "base" isotope ${ }^{198} \mathrm{Hg}$. For many processes, such as advection by fluid flow and mixing, isotopic delta values can be manipulated directly as a tracer. However, to calculate the expression of an isotope fractionation in the steady-state solution to a web of chemical reactions requires that we simulate the impact of the fractionation on the budgets of the different isotopes, as the simplest way to come up with a delta value.

The way that the model treats the isotopes differs from reality, for a numerical convenience, following a technique developed by Ernst Maier-Reimer in HAMOCC many years ago for carbon isotope ratios (Maier-Reimer, 1984). In the real world, the total $\mathrm{Hg}$ concentration is comprised of multiple isotopes. In the model, the concentrations of $\mathrm{Hg}$ in the

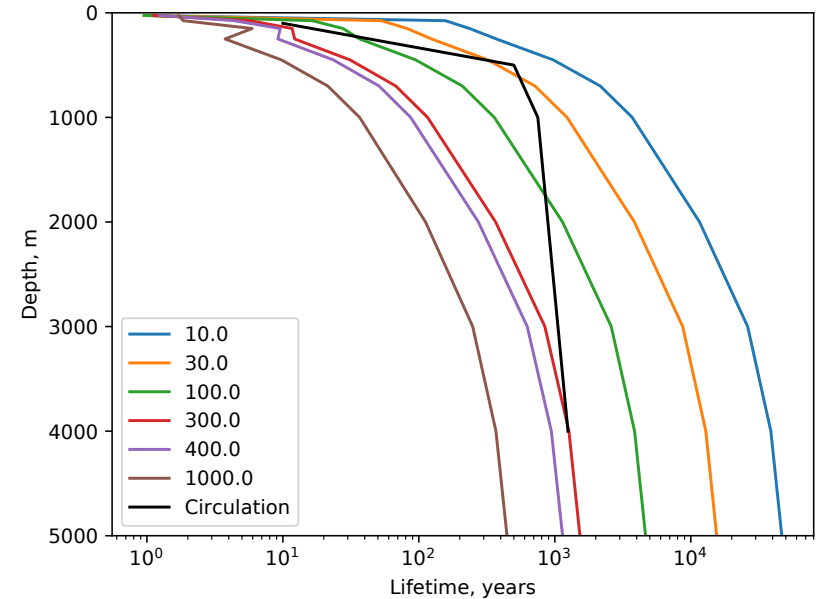

Figure 7. Profiles of the turnover time of $\mathrm{Hg}$ (II) with respect to transiting through the system on sinking particles, as a function of the sinking velocity in the legend, in meters per year $\left(\mathrm{m} \mathrm{yr}^{-1}\right)$. The black line is the water age since exposure to the atmosphere derived from the ${ }^{14} \mathrm{C}$ distribution (Gebbie and Huybers, 2012).

ocean are taken as that of a base isotope. Then the entire $\mathrm{Hg}$ cycle in the model is duplicated, and the kinetic constants slightly altered, to represent the behavior of a different $\mathrm{Hg}$ isotope. Each isotopic field corresponds to how the total $\mathrm{Hg}$ field would behave if it were entirely comprised of its particular $\mathrm{Hg}$ isotope, subject to slightly altered sources and kinetic rate constants for that isotope.

The deviations of the fields for the other isotopes are represented as ratios relative to the base field, and presented in per mill (\%o), where the ratio of the "standard" is 1 rather than the particular ratio of the isotopic reference standard for natural samples. The relative differences, represented as ratios in per mill, are the same between variations in the isotopes in reality and between the altered fields in the model, even though the concentrations are different between the two cases. The advantage of this scheme is that the fields representing the different isotopes are subjected to similar computational rounding errors, because their values are similar. Also, it is simpler to simulate the behavior of total $\mathrm{Hg}$ in a single field, rather than as a more complicated sum of isotopic concentrations as in reality.

Because the chemical speciation of $\mathrm{Hg}$ is solved for each time step, there is no need to advect the concentrations of chemical species such as MMHg. The advection scheme in the model carries the total concentrations representing each isotope. Each isotope field is divided into the different $\mathrm{Hg}$ species, assuming steady state and using the web of kinetic rate constants appropriate to that isotope. The slightly altered speciation of one isotope relative to another, and the slightly differing sources and sinks for that isotope, lead to slight differences between the abundances of each isotope overall in the Hg pool. 
Mass-dependent fractionation processes are imposed on all isotopic systems, with the rates depending on how much heavier an isotope is than mass 198. Mass-independent fractionations in the ocean are applied only to the ${ }^{199} \mathrm{Hg}$ system, while the ${ }^{200} \mathrm{Hg}$ system is driven only by different isotopic signatures of wet $(\mathrm{Hg}(\mathrm{II}))$ vs. dry $(\mathrm{Hg}(0))$ deposition. Mass independent fractionations are calculated by subtracting the expected mass-dependent fractionation, to produce a composite quantity $\Delta$ value. The solver finds the impact of the fractionation mechanisms on the steady-state isotopic signatures in the $\mathrm{Hg}$ system: the expression of the isotope effects within the kinetic ocean $\mathrm{Hg}$ cycle.

\subsection{The anthropogenic perturbation}

Human activity has resulted in significantly increased $\mathrm{Hg}$ emission to the global biosphere since about 1850 (Streets et al., 2011, 2017; Amos et al., 2013; Horowitz et al., 2014), which has lead to an increase in $\mathrm{Hg}$ deposition to the ocean. Because of the tendency for $\mathrm{Hg}$ to recycle in the environment, the relationship between emissions and deposition is not simple and immediate, but rather reflects the entire cumulative emission and re-emission of $\mathrm{Hg}$. Guided by a reconstructed history of atmospheric $\mathrm{Hg}$ through time (Streets et al., 2017), we subject our model to a 4-fold increase in $\mathrm{Hg}$ deposition, following an initial spin-up equilibration period of 10000 years. The beginning of the anthropogenic period corresponds to approximately the year 1850 . We show natural steady-state results from model year 1850, which are useful for understanding how the ocean $\mathrm{Hg}$ cycle works, and contemporary results from model year 2010, for comparison with field measurements. Anthropogenically enhanced deposition is continued at a constant rate until the year 2100, after which we follow two scenarios: an abrupt and unrealistic return to natural $\mathrm{Hg}$ deposition fluxes, useful to determine the time constant of the oceanic recovery, and a "hangover" scenario in which an abrupt cessation of human $\mathrm{Hg}$ emissions triggers a gradual slowdown of enhanced deposition, over an ocean overturning timescale of 1000 years.

\subsection{Method limitations}

The steady-state assumption in the Hg solvers limits the ability of $\mathrm{Hg}$-HAMOCC to explore detailed shallow-water interactions of turbulence, ventilation, and photochemistry, and the physics of the tracer advection code preclude exploration of processes on short timescales, such as the seasonal cycle near the surface. The model allows us to explore the interaction of the $\mathrm{Hg}$ chemistry and particle adsorption with the ocean circulation on long timescales.

A peculiarity of the surface ocean solver is that fluxes of $\mathrm{Hg}$ across the sea surface are always locally balanced, by construction, neglecting the impact of any upwelling $\mathrm{Hg}$ driving sea surface $\mathrm{Hg}$ concentrations and evasion rates to higher values. Similarly to the treatment of $\mathrm{O}_{2}$ gas in
HAMOCC (Maier-Reimer and Bacastow, 1990), the Hg concentrations in the surface box $(50 \mathrm{~m})$ are maintained at atmospheric saturation through the iterations in the advection scheme. The concentrations in the box below that (to $125 \mathrm{~m}$ ) are comprised of $25 \%$ saturation while the other $75 \%$ is driven by subsurface advection. Because $\mathrm{Hg}$ concentrations in the top box are determined by a balance of fluxes with the atmosphere, in places where surface divergence brings up $\mathrm{Hg}$ from below, the advective upwelling source is missed by $\mathrm{Hg}$ HAMOCC, which will underestimate the Hg surface concentrations and degassing rates somewhat. To use the model to simulate a transient uptake of $\mathrm{Hg}$ by the ocean in response to a change in the surface rain rate, we can track the change in global ocean inventory of $\mathrm{Hg}$ with time, but the fluxes determined by the solver at the air-sea interface will balance to zero, locally and at all times, defiant of the net fluxes that are filling the deep ocean with $\mathrm{Hg}$. The top box of the model $(50 \mathrm{~m})$ serves as a sort of boundary condition for $\mathrm{Hg}$.

\section{Results}

\subsection{Particle sinking versus the overturning circulation}

There are two competing mechanisms for $\mathrm{Hg}$ invasion into the deep ocean: advection by the overturning circulation and the flux of $\mathrm{Hg}$ adsorbed on sinking particles. We use our model to explore the interaction of these pathways. There are two end-member cases to consider; one with particles dominating the distribution and transport of $\mathrm{Hg}$, and the other with circulation dominating. The particle-flux dominating end-member conditions can be achieved in $\mathrm{Hg}$-HAMOCC by disabling the advection of the $\mathrm{Hg}$ tracers (Fig. 8, orange line). In the steady state, in order to achieve $\mathrm{Hg}$ concentrations that are not changing through time, the vertical flux of $\mathrm{Hg}$ through the water column must be the same at all depth levels. The flux of sinking POC decreases with depth in the ocean due to degradation. The abundant POC sinking flux in the surface ocean carries the same $\mathrm{Hg}$ sinking flux as the rarefied POC sinking flux in the deep sea.

This means that in the steady state, the POC in the deep sea has to carry more $\mathrm{Hg}$ than it would in the surface ocean. The adsorbed $\mathrm{Hg}$ is linearly related to the dissolved $\mathrm{Hg}$ by the adsorption Eq. (1). Rearranging Eq. (1) gives the following:

$[\mathrm{Hg}-\mathrm{P}]=[\mathrm{Hg}(\mathrm{II})] K_{\mathrm{d}}[\mathrm{POC}]$.

If we take the sinking Hg-P flux to be proportional to [Hg$\mathrm{P}]$ (assuming a uniform sinking velocity), then a decrease in the flux of POC (proportional to [POC] for the same reason) requires a higher dissolved $[\mathrm{Hg}(\mathrm{II})]$. The result is that, in the steady state, $\mathrm{Hg}$ concentrations rise with depth in the ocean, to compensate for the decrease in sinking POC flux. A smaller POC sinking flux will have to carry a higher $\mathrm{Hg}$ concentration in order to sustain the required depth-uniform 
(a) Global mean

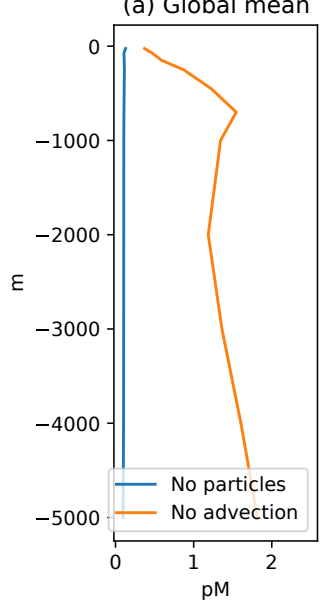

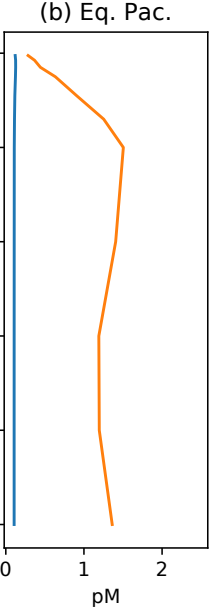

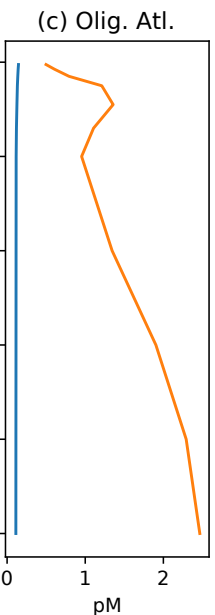

Figure 8. Profiles of mean $\mathrm{Hg}$ concentration in (preanthropogenic) steady state, as a function of depth in the ocean, in equilibrium, for the end-member cases of no particles (blue lines), and no advection (orange lines). (a) Panels are global mean, others are from locations in Fig. 4. If there were no particles, the $\mathrm{Hg}$ concentration would be homogenized throughout the ocean by the circulation. If there were no circulation, the concentration in the steady state would increase with depth in the ocean, because there are fewer sinking particles at depth, so the $\mathrm{Hg}$ abundance per particle has to increase, as does therefore the dissolved $\mathrm{Hg}$ concentration in the ocean.

$\mathrm{Hg}$ flux, and the higher adsorbed $\mathrm{Hg}$ concentration requires a higher $\mathrm{Hg}$ concentration in the water column.

The other end-member case comes much closer to the observed distribution of $\mathrm{Hg}$ in the deep ocean. When circulation dominates, and particle transport of $\mathrm{Hg}$ is disabled, the $\mathrm{Hg}$ concentrations maintained in the surface ocean (by balancing evasion against deposition) are imposed on the deep ocean, resulting in a nearly uniform distribution of $\mathrm{Hg}$ throughout the ocean (Fig. 8, blue line). There are some regional variations in $\mathrm{Hg}$ in this scenario, but they are not systematic, as compared to the clear Pacific-Atlantic differences exhibited by nutrient-type elements (concentrated in the Pacific) versus those exhibited by strongly scavenged elements like $\mathrm{Al}$ (concentrated in the Atlantic, where deposition is more intense).

The balance between advection versus sinking particles affects the uptake of anthropogenic $\mathrm{Hg}$ by the ocean. Profiles of total $\mathrm{Hg}$ changes from the preanthropogenic period to the present day, after 130 years of enhanced $\mathrm{Hg}$ deposition (to 2010), are shown in Fig. 3. If particles are neglected or sink so slowly as to be negligible in the $\mathrm{Hg}$ cycle, there is a sharp surface spike in $\mathrm{Hg}$ concentrations in the model simulation of the present day (2010), due to increased deposition. The increasing importance of particle transport tends to moderate a surface ocean spike, while transferring much of the anthropogenic $\mathrm{Hg}$ load to a subsurface maximum corresponding to the location of POC degradation in the thermocline. Particulate $\mathrm{Hg}$ transport to depth is required in order to simulate a subsurface maximum in $\mathrm{Hg}$ concentration, as observed in the

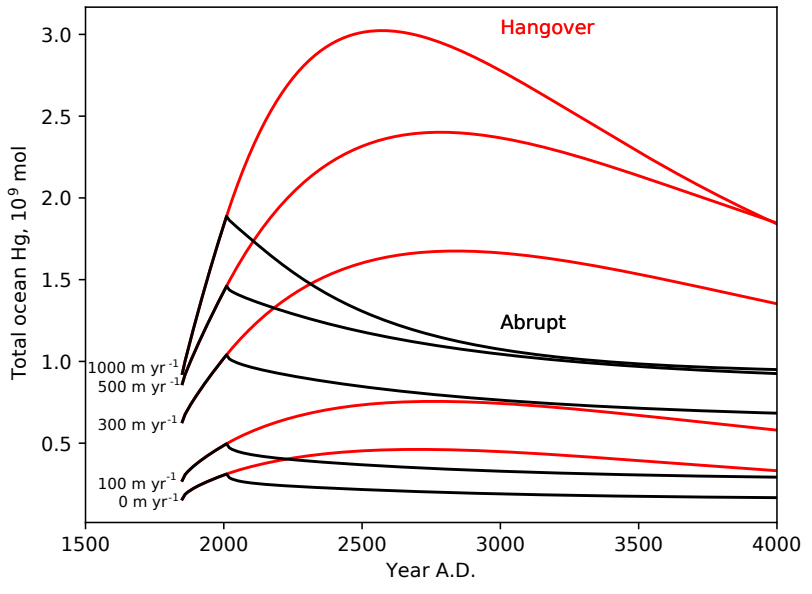

Figure 9. Time series of the ocean load of $\mathrm{Hg}(\mathrm{Mmol})$, in response to 250 years of enhanced $\mathrm{Hg}$ (II) deposition (1850-2100), followed by abrupt return to natural $\mathrm{Hg}$ deposition rates, or 1000-year winddown in anthropogenic deposition due to recycling from the ocean.

present-day real ocean. In the steady state, with no anthropogenic enhanced deposition, a somewhat slower Hg sinking flux would still generate a subsurface maximum, but it is harder to have a subsurface maximum at the end of a period of enhanced $\mathrm{Hg}$ deposition, such as today.

Figure 9 shows the total ocean inventory of anthropogenic $\mathrm{Hg}$ throughout the anthropogenic deposition period (ending in the year 2100) and beyond, as a function of the Hg particle sinking velocity. Particle transport has only a minor impact on the global rate of $\mathrm{Hg}$ uptake during the Anthropocene stage, but strong particle transport has the effect of sequestering the anthropogenic $\mathrm{Hg}$ deeper in the ocean (Fig. 3), where it is retained somewhat longer than in models with less particle transport. The model, when forced with an instantaneous end to anthropogenic emissions, predicts that the ocean will continue degassing $\mathrm{Hg}$ for 1000 years. When this prediction is turned around, to impose a condition that the $\mathrm{Hg}$ deposition rate declines over 1000 years after the year 2100 , the duration of the anthropogenic $\mathrm{Hg}$ load on the oceans increases to several thousand years.

\subsection{Model sensitivity to reaction kinetics}

For each of eight kinetic rate constant parameters in the $\mathrm{Hg}$ system, we ran simulations to a natural steady state with factor-of-2 increases and decreases in each parameter in turn, as shown in Fig. 10. In general, increasing the rate constant for a given reaction will increase the concentration of the product and decrease that of the reactant. The other species' concentrations will also change in the new steady-state balance. The concentration of $\mathrm{Hg}$ overall depends on the rate of $\mathrm{Hg}$ removal from the system, primarily by gas evasion of the minor species $\mathrm{Hg}(0)$, with secondary sinks by DMHg evasion and $\mathrm{Hg}(\mathrm{II})$ adsorption onto sinking particles (Table 1). 
(a)

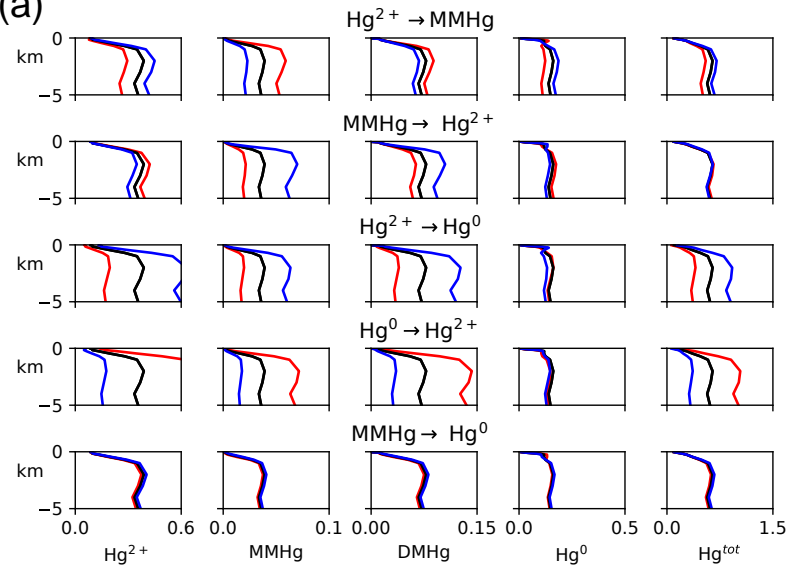

(b)

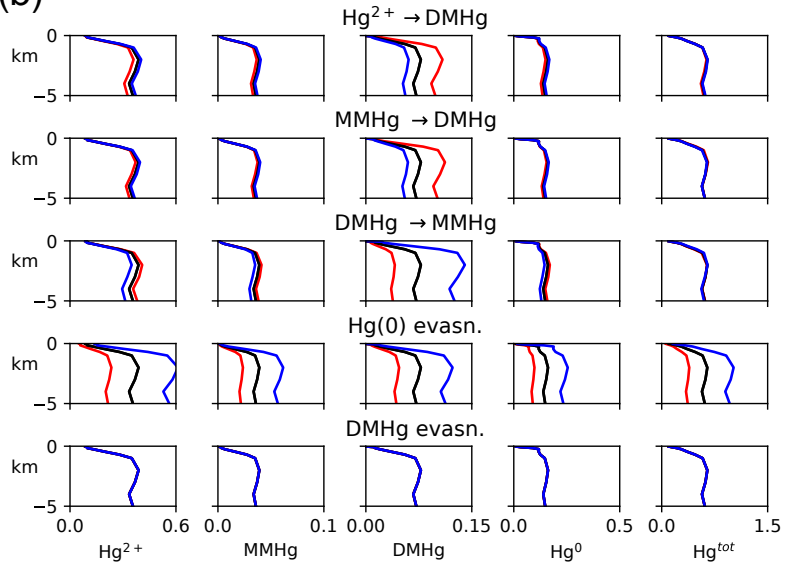

Figure 10. Model sensitivity to kinetic rate constants in the Hg system. For each kinetic rate constant as indicated in the centered titles, global mean concentrations of each species are given in the four plots in that row, as indicated by the labels at the top of each column. Black lines represent the base case, and red and blue represent factors of 2 higher and lower for that kinetic rate constant, respectively.

Increasing the rate of $\mathrm{MMHg}$ production from $\mathrm{Hg}(\mathrm{II})$, for example, decreases $[\mathrm{Hg}(\mathrm{II})]$ and increases $[\mathrm{MMHg}]$. The concentration of DMHg increases due to its close coupling with MMHg (see Fig. 1).

Changes in the rate constants that produce or consume $\mathrm{Hg}(0)$ tend to result in larger changes in $\mathrm{Hg}$ concentrations than the rate constants for reactions that involve $\mathrm{DMHg}$, because $\mathrm{Hg}(0)$ is responsible for a larger fraction of the gas evasion flux. The exception is reductive degradation of $\mathrm{MMHg}$ to $\mathrm{Hg}(0)$, which occurs primarily in the surface ocean, changing the MMHg concentration there without changing concentrations appreciably in the deep ocean. The highest model sensitivity in the suite of runs is to the rate of evasion of $\mathrm{Hg}(0)$, which drives large changes in the total $\mathrm{Hg}$ concentration of the entire ocean, in the steady state.
Table 1. Fluxes (in $\mathrm{Mmol} \mathrm{yr}^{-1}$ ) from model kinetic rate constant sensitivity experiments.

\begin{tabular}{lrrrr}
\hline Experiment & $\begin{array}{r}\mathrm{Hg}(0) \\
\text { evasion }\end{array}$ & $\begin{array}{r}\text { DMHg } \\
\text { evasion }\end{array}$ & $\begin{array}{r}\mathrm{HgP} \\
\text { surf }\end{array}$ & $\begin{array}{r}\mathrm{HgP} \\
\text { seafloor }\end{array}$ \\
\hline Base & 3.69 & 0.07 & 1.12 & 0.57 \\
$\mathrm{Hg}(\mathrm{II}) \rightarrow \mathrm{MM} \mathrm{Hg} 2 \times$ & 3.77 & 0.08 & 1.03 & 0.47 \\
$0.5 \times$ & 3.65 & 0.06 & 1.17 & 0.64 \\
$\mathrm{MMHg} \rightarrow \mathrm{Hg}(\mathrm{II}) 2 \times$ & 3.67 & 0.06 & 1.14 & 0.63 \\
$0.5 \times$ & 3.71 & 0.07 & 1.10 & 0.49 \\
$\mathrm{Hg}(\mathrm{II}) \rightarrow \mathrm{Hg}(0) 2 \times$ & 3.75 & 0.06 & 1.06 & 0.43 \\
$0.5 \times$ & 3.66 & 0.07 & 1.15 & 0.66 \\
$\mathrm{Hg}(0) \rightarrow \mathrm{Hg}(\mathrm{II}) 2 \times$ & 3.68 & 0.07 & 1.13 & 0.66 \\
$0.5 \times$ & 3.70 & 0.07 & 1.11 & 0.46 \\
$\mathrm{MMHg} \rightarrow \mathrm{Hg}(0) 2 \times$ & 3.72 & 0.06 & 1.10 & 0.56 \\
$0.5 \times$ & 3.66 & 0.08 & 1.14 & 0.59 \\
$\mathrm{Hg}(\mathrm{II}) \rightarrow \mathrm{DMHg} 2 \times$ & 3.66 & 0.12 & 1.10 & 0.53 \\
$0.5 \times$ & 3.71 & 0.04 & 1.12 & 0.62 \\
$\mathrm{MMHg} \rightarrow \mathrm{DMHg} 2 \times$ & 3.70 & 0.07 & 1.12 & 0.62 \\
$0.5 \times$ & 3.69 & 0.07 & 1.12 & 0.50 \\
$\mathrm{DMHg} \rightarrow \mathrm{MMHg} 2 \times$ & 3.68 & 0.08 & 1.11 & 0.53 \\
$0.5 \times$ & 3.70 & 0.06 & 1.12 & 0.60 \\
$\mathrm{Hg}(0)$ Evasion $2 \times$ & 4.14 & 0.04 & 0.70 & 0.40 \\
$0.5 \times$ & 2.96 & 0.10 & 1.81 & 1.06 \\
$\mathrm{DMHg}$ Evasion $2 \times$ & 3.65 & 0.06 & 1.17 & 0.67 \\
$0.5 \times$ & 3.65 & 0.06 & 1.17 & 0.67 \\
\hline
\end{tabular}

In general, the rates of chemical transformation of $\mathrm{Hg}$ are much faster than that of the ocean overturning circulation, so the distribution of $\mathrm{Hg}$ species at any location reflects a local balance between sources and sinks of each form of Hg. However, reactions at the sea surface that provide a pathway for $\mathrm{Hg}$ evasion into the atmosphere have the potential to alter the $\mathrm{Hg}$ concentrations throughout the ocean in the steady state.

\subsection{Isotopic fractionation}

Isotopic fractionations in the $\mathrm{Hg}$ cycle can be "expressed" in the isotopic signatures of $\mathrm{Hg}$ species, or not, depending on how the fractionating process fits into the network of reactions in the cycle. Figure 11 shows the isotopic compositions of $\mathrm{Hg}$ species resulting from a variety of fractionation mechanisms, in schematic diagrams of the ocean $\mathrm{Hg}$ cycle. Red numbers indicate isotopic fractionations and black numbers show global mean oceanic isotopic compositions. The results represent preanthropogenic steady state. The model is run to equilibrium for each of seven fractionation mechanisms in isolation, and finally for all mechanisms combined. For ease of comparison with oceanic measurements, all scenarios are subject to fractionation in $\mathrm{Hg}$ deposition, as indicated by the red numbers next to these fluxes. Figure 12 shows depth profiles of isotopic composition. Figure 13 shows maps of isotopic compositions, at the sea surface and at depth.

A guiding principle in understanding these results is that in the steady state the isotopic composition of the sinking 


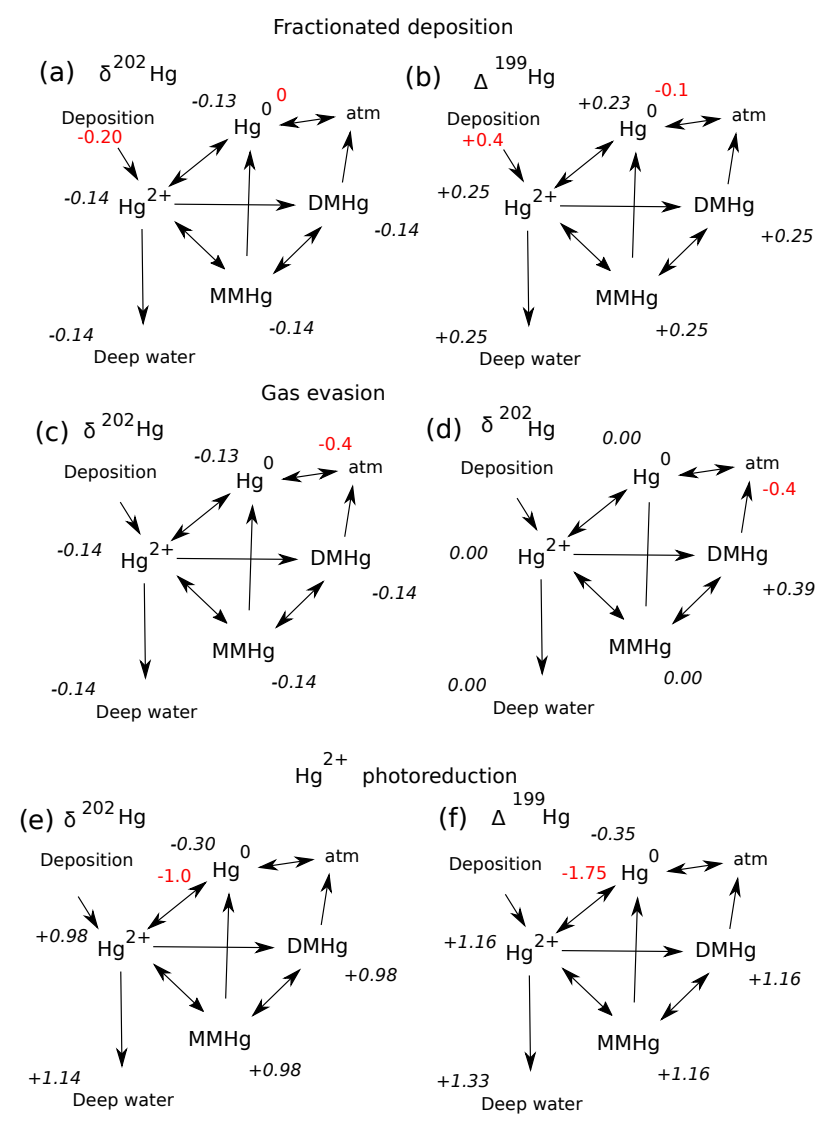

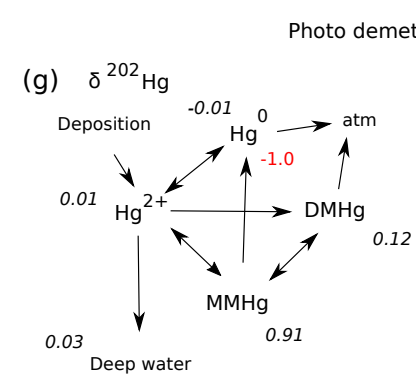

(h) $\Delta{ }^{199} \mathrm{Hg}$
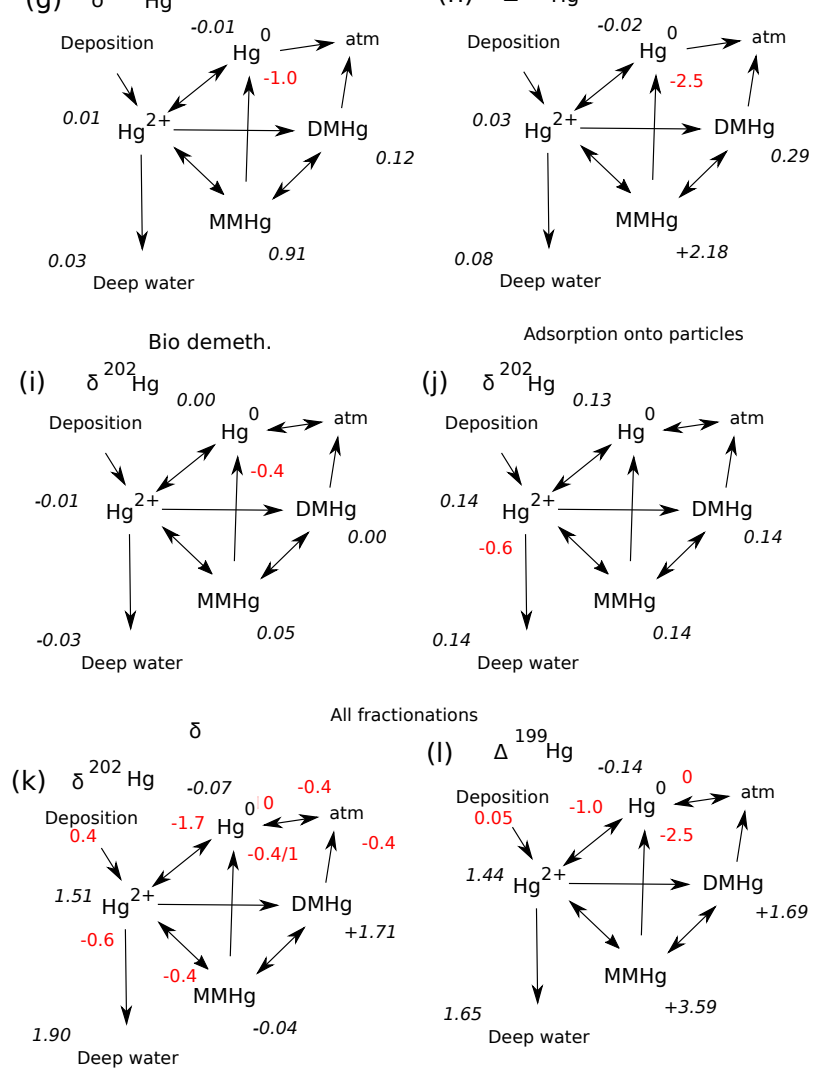

Figure 11. Schematic of the expression of isotopic fractionations on the global mean sea surface isotopic signatures of the $\mathrm{Hg}$ species in the model, for preanthropogenic steady state. Fractionation epsilon values are shown in red, expressed as per mill differences in the ${ }^{202} \mathrm{Hg} /{ }^{198} \mathrm{Hg}$ ratio. Resulting global surface average $\delta^{202} \mathrm{Hg}$ values for each species are in black italics. Isotopic compositions of the wet and dry deposition are preanthropogenic estimates from Sun et al. (2016 \#9). (a) The signature of mass-dependent fractionation in $\mathrm{Hg}^{2}=\mathrm{deposition}_{\text {. (b) Mass }}$ independent $\Delta{ }^{199} \mathrm{Hg}$ signature of wet deposition. (c) Fractionation associated with $\mathrm{Hg}(0)$ evasion (Wiederhold et al., 2010). (d) Fractionation applied to DMHg evasion (assuming the same fractionation as for $\mathrm{Hg}(0)$ evasion). (e, f) Fractionation is applied in the reduction of $\mathrm{Hg}$ (II) to form $\mathrm{Hg}(0)$ (Kritee et al., 2007). (g, f) Fractionation in biological and photodemethylation or photoreduction of $\mathrm{MMHg}$ to form $\mathrm{Hg}(0)$. $\mathrm{The}$ $\varepsilon^{202}$ isotopic fractionation is taken to be a weighted average of biological (Kritee et al., 2007) and photochemical fractionation (Bergquist and Blum, 2007; Blum et al., 2014), while the $\varepsilon^{199}$ is from Bergquist and Blum (2007). (g) Fractionation of biological MMHg production from Rodriguez-Gonzalez et al. (2009). (h) Biological demethylation from Kritee et al. (2007). (i) Fractionation during adsorption of Hg(II) onto POC is from Wiederhold et al. (2010).

fluxes have to balance the isotopic compositions of the inputs of $\mathrm{Hg}(\mathrm{II})$ from rain and $\mathrm{Hg}(0)$ from atmosphere-sea surface exchange. A fractionation mechanism that alters the isotopic signature of one of the sink fluxes will require the steadystate signatures of the other sink fluxes to change in compensation. Then the values of the other species (MMHg and $\mathrm{Hg}(\mathrm{II}))$ are pulled in various ways by their connections with the two potential gases $\mathrm{Hg}(0)$ and $\mathrm{DMHg}$.

\subsubsection{Gas evasion fractionations}

The schematic diagram in Fig. 11a shows the fractionation associated with evasion of $\operatorname{Hg}(0)$ to the atmosphere. The lighter isotope reacts faster (as is typical), leaving a dis- solved $\mathrm{Hg}(0)$ pool that has residually higher $\delta^{202} \mathrm{Hg}$, by about $+0.17 \%$. The $\mathrm{Hg}(0)$ evasion flux has a $\delta^{202} \mathrm{Hg}$ value of $-0.23 \%$ (from the source isotopic composition of $0.17 \%$ o adjusted for the fractionation of $-0.4 \%$ ), which is lower than the weighted sum of the input fluxes $(+0.13 \%$ ) and must be balanced by evasion of high $\delta^{202} \mathrm{Hg}$ DMHg and burial of deep water $\mathrm{Hg}(\mathrm{II})$ adsorbed onto particles. The depth dependence of the response is weak (Fig. 12a), but variations in particle export from the surface ocean perturb the spatial uniformity of $\delta^{202} \mathrm{Hg}(0)$ (Fig. 13a). Fractionation in DMHg degassing (Fig. 11b) is similar in that the $\delta^{202} \mathrm{Hg}$ of the degassing fractionating species (DMHg) becomes more positive in the residual fraction. Because $\mathrm{DMHg}$ is not re- 

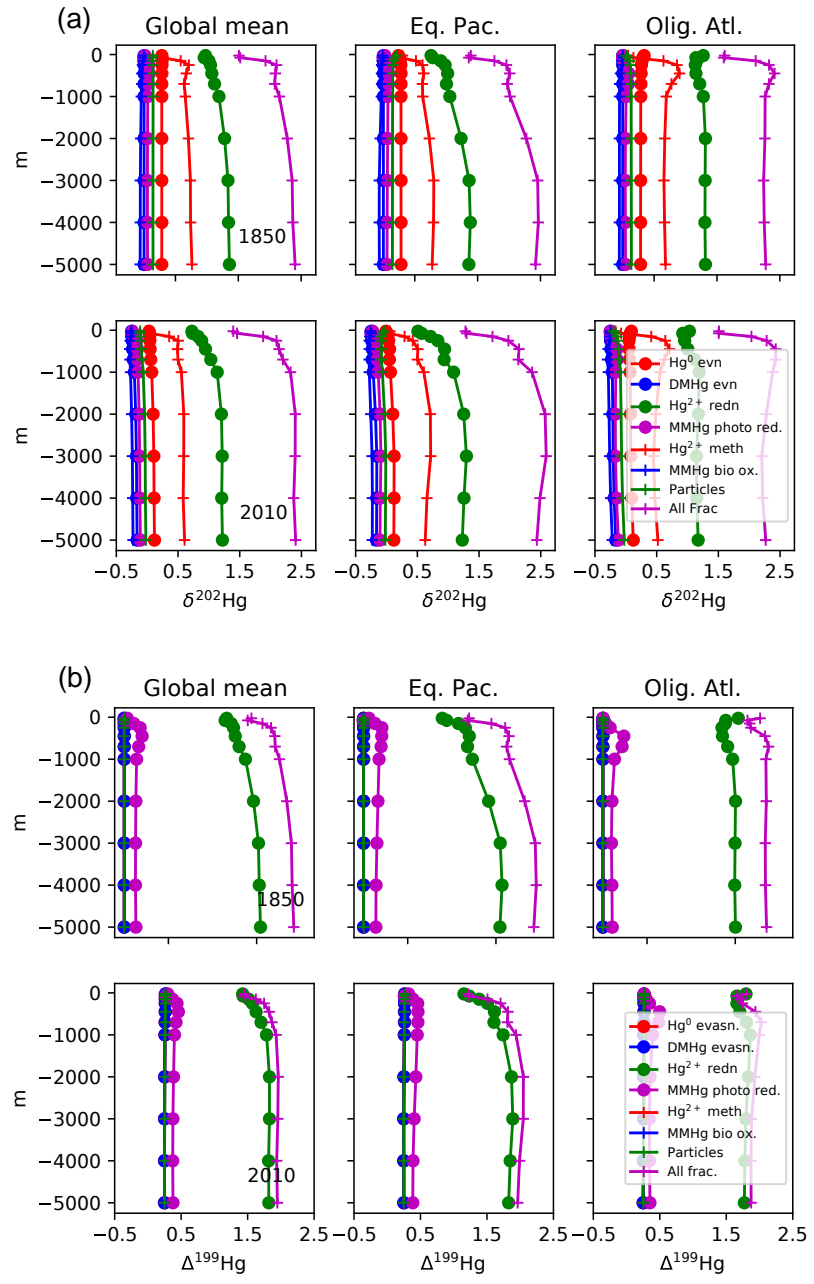

Figure 12. Profiles of $\delta^{202} \mathrm{Hg}$ (II) and $\Delta^{199} \mathrm{Hg}$ (II) for different fractionation scenarios: global mean and for the locations in Fig. 4.

turned to the $\mathrm{Hg}$ pool as quickly in the model as $\mathrm{Hg}(0)$, the isotopic deviation in DMHg does not pass to the other pools, which reflect the balance of the source fluxes.

\subsubsection{Reaction fractionations}

The expression (or not) of a fractionation in a specific reaction pathway in the $\mathrm{Hg}$ cycle depends on the web of reactions between the species and the mass balance constraints. For example, fractionation during the reduction step from $\mathrm{Hg}$ (II) to $\mathrm{Hg}(0)$ (Fig. $11 \mathrm{c}$ and d) pulls the $\delta^{202} \mathrm{Hg}$ value of $\mathrm{Hg}(0)$ to a lower value, requiring a positive excursion in the $\delta^{202} \mathrm{Hg}$ value of $\mathrm{DMHg}$ to balance the overall evasion isotopic ratio against that of deposition. The $\delta^{202} \mathrm{Hg}$ values of $\mathrm{Hg}(\mathrm{II})$ and $\mathrm{MMHg}$ follow DMHg to higher values. This fractionation does lead to surface-deep isotopic contrast in $\delta^{202} \mathrm{Hg}$, as well as regional variations at the sea surface and in the deep ocean, reflecting differences in particle scavenging in productive areas and the differing fractionation due to photo- chemistry in the surface ocean. The $\Delta^{199} \mathrm{Hg}$ isotopic system behaves similarly, with differences due to different isotopic signatures of wet and dry $\mathrm{Hg}$ deposition, and with the difference that most of the surface-deep and deep Pacific-Atlantic contrasts in $\Delta^{199} \mathrm{Hg}$ values can be attributed to this fractionation mechanism alone (Fig. 12).

Fractionation in the photochemical $\mathrm{MMHg} \rightarrow \mathrm{Hg}(0)$ reaction step (Fig. 11e and f) causes an increase in the $\delta^{202} \mathrm{Hg}$ value of $\mathrm{MMHg}$, which is passed on to $\mathrm{DMHg}$ and $\mathrm{Hg}(\mathrm{II})$. The $\mathrm{Hg}(0)$ evasion flux has only slightly lower $\delta^{202} \mathrm{Hg}$ than the mean deposition flux, balanced by slightly higher $\delta^{202} \mathrm{Hg}$ in the DMHg evasion and $\mathrm{Hg}$ (II) loss on particles. In contrast to $\mathrm{Hg}(\mathrm{II})$ reduction, $\mathrm{MMHg}$ reduction does not lead to surface-deep $\delta^{202} \mathrm{Hg}$ contrast in the $\mathrm{Hg}$ (II) (Figs. 12 and 13), but it does lead to an enrichment in $\Delta^{199} \mathrm{Hg}$ of MMHg in the surface ocean (Fig. 14), consistent with the measurements of fish $\mathrm{Hg}$ by Blum et al. (2013), and in contrast with the apparent $\Delta{ }^{199} \mathrm{Hg}$ of $\mathrm{Hg}$ (II) in particles from the upper ocean derived from Motta et al. (2018).

Fractionation in MMHg production (Fig. 11g) results in a decrease in $\delta^{202} \mathrm{Hg}$ of MMHg, forcing $\delta^{202} \mathrm{Hg}$ values of $\mathrm{Hg}(\mathrm{II})$ to increase in compensation. The higher $\delta^{202} \mathrm{Hg}$ values of $\mathrm{Hg}(\mathrm{II})$ on sinking particles offsets slightly lower $\delta^{202} \mathrm{Hg}$ values of $\mathrm{Hg}(0)$ and $\mathrm{DMHg}$ evasion to the atmosphere. Fractionation in biologically mediated MMHg degradation (Fig. 11h) acts in the opposite sense for $\delta^{202} \mathrm{Hg}$ values due to the opposite direction of the reaction. Both fractionation mechanisms lead to horizontal heterogeneity of $\delta^{202} \mathrm{Hg}$ in the surface ocean, and a contrast between deep Atlantic and Pacific values (Figs. 12 and 13). These mechanisms do not impact $\Delta^{199} \mathrm{Hg}$ values because they are purely massdependent fractionations. $\mathrm{Hg}$ (II) adsorption onto particles generates horizontal gradients in $\delta^{202} \mathrm{Hg}$ of the surface ocean (Fig. 13), but in the global mean the fractionation between the surface ocean and deep ocean is very small (Fig. 12).

The $\Delta^{200} \mathrm{Hg}$ isotopic system does not fractionate internally in the ocean, but rather the ocean acts to integrate the isotopic signature of the surface forcing mechanisms (wet and dry deposition). If the deposition is taken to be spatially uniform, the oceanic distribution of $\Delta^{200} \mathrm{Hg}$ values will also be uniform throughout the ocean (Fig. 15). The global mean $\Delta^{200} \mathrm{Hg}$ values of the ocean might serve as a constraint on the relative magnitudes of the wet and dry fluxes (Fig. 16). Regional variations in $\Delta^{200} \mathrm{Hg}$ values of the ocean may arise from heterogeneity in the deposition fluxes. In Fig. 17, the deposition flux of $\mathrm{Hg}$ (II) was doubled in each of the Atlantic, Pacific, and Indian basins in turn, and the model was run to equilibrium. Variations in the $\Delta^{200} \mathrm{Hg}$ values of deposition into the surface waters of the basin can also be seen, in a muted way, in the $\Delta^{200} \mathrm{Hg}$ values at $3 \mathrm{~km}$ depth in the ocean. However, it must be noted that the predicted variations are small $(<0.01 \% o)$ and with current analytical methods they would be impossible to measure. 
(a)

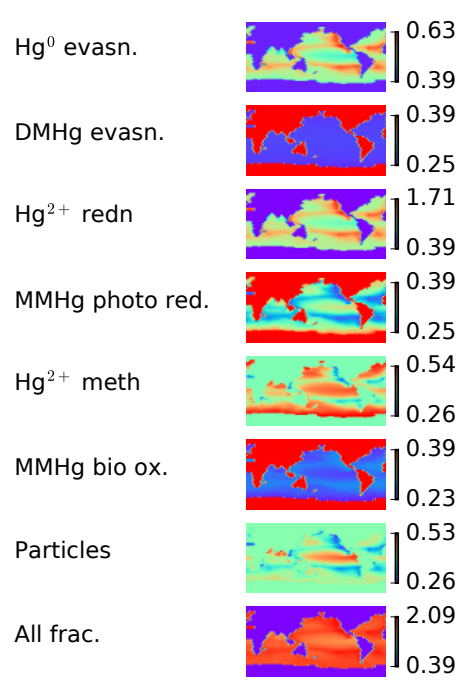

(c)

$\mathrm{Hg}^{0}$ evasn.

DMHg evasn.

$\mathrm{Hg}^{2+}$ redn

MMHg photo red.

$\mathrm{Hg}^{2+}$ meth

MMHg bio ox.

Particles

All frac.

\section{Surface}

Surface
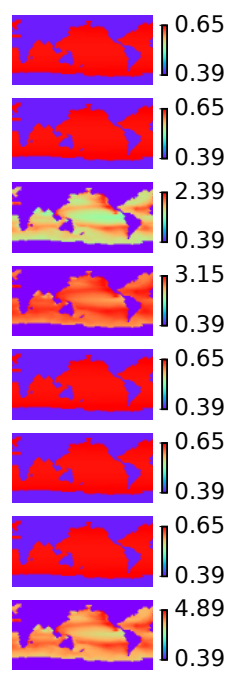

$3 \mathrm{~km}$

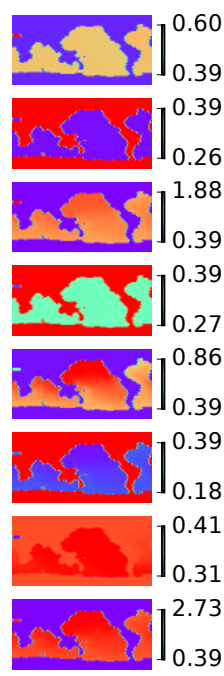

$3 \mathrm{~km}$

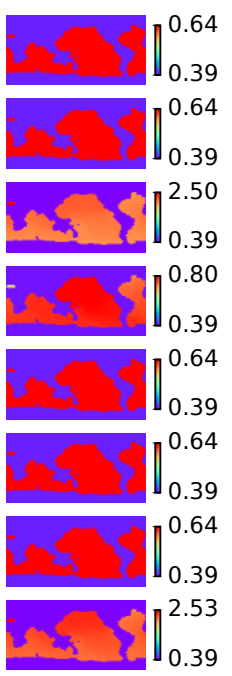

(b)

$\mathrm{Hg}^{0}$ evn

DMHg evn

$\mathrm{Hg}^{2+}$ redn

MMHg photo red.

$\mathrm{Hg}^{2+}$ meth

MMHg bio ox.

Particles

All frac.
Surface

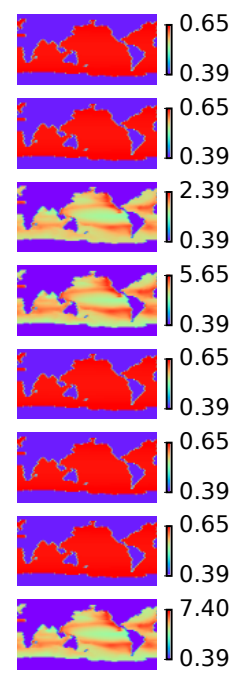

$3 \mathrm{~km}$

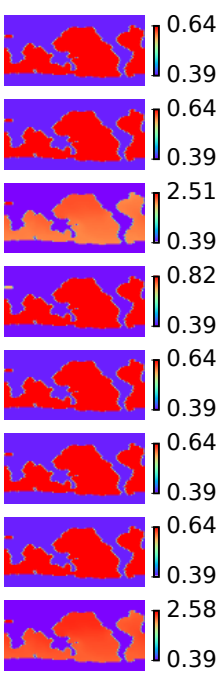

Figure 13. (a) Maps of $\delta^{202} \mathrm{Hg}$ (II) at the sea surface (left) and at $3 \mathrm{~km}$ depth (right) for different fractionation scenarios. (b) Maps of $\Delta^{199} \mathrm{Hg}(\mathrm{II})$ at the sea surface (left) and at $3 \mathrm{~km}$ depth (right) for different fractionation scenarios. (c) $\mathrm{Maps}$ of $\Delta^{199} \mathrm{Hg}$ of $\mathrm{MMHg}$ at the sea surface (left) and at $3 \mathrm{~km}$ depth (right) for different fractionation scenarios.

\section{Conclusions}

We have embedded a model of $\mathrm{Hg}$ chemistry and dynamics into the HAMOCC offline ocean tracer advection model, including treatment of isotopic fractionation of $\mathrm{Hg}$ in the ocean $\mathrm{Hg}$ cycle. The efficiency of the model makes it possible to do numerous sensitivity experiments for testing hypotheses and developing intuition about this complex system: 55 simulations of over $10 \mathrm{kyr}$ each are presented in this paper.

The model demonstrates that the $\mathrm{Hg}$ cycle in the ocean is closer to an advective end-member than to a system in which transport on sinking particles dominates. The interplay of advection by fluid flow and sinking of $\mathrm{Hg}$ adsorbed on sinking particles is illustrated by end-member cases in which one or the other dominates. In an advection-dominated case in which particle transport is disabled, the $\mathrm{Hg}$ concentration in steady state is relatively uniform with depth, displaying the same pattern as for salinity. In a particle-dominated scenario in which fluid advection of $\mathrm{Hg}$ is disabled, the concentration of $\mathrm{Hg}$ in steady state increases with depth, in proportion to the decrease in the POC sinking flux with depth (due to particle decomposition). This is because in the steady state 

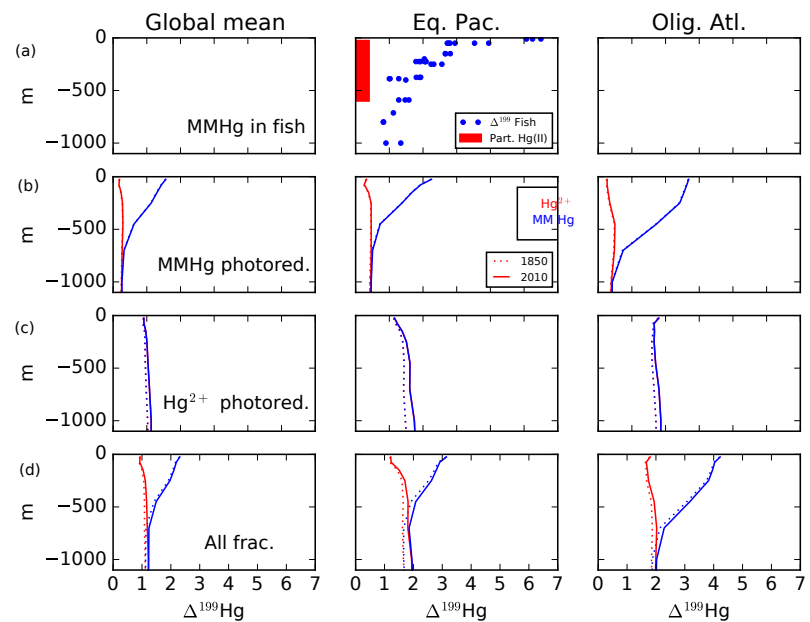

Figure 14. Profiles of $\Delta^{199} \mathrm{Hg}$ of $\mathrm{MMHg}$ and $\mathrm{Hg}$ (II) for photochemical fractionation mechanisms. Panel (a) are observations of MMHg $\Delta^{199} \mathrm{Hg}$ inferred from measurements of fish (Blum et al., 2013), and $\Delta 199 \mathrm{Hg}$ for $\mathrm{Hg}(\mathrm{II})$ from measurements of $\mathrm{Hg}$ on particles (Motta et al., 2018 \#6704). Panel (b) shows model results with $\mathrm{MMHg}$ photoreduction, using isotope fractionation from Bergquist and Blum (2007). Panel (c) shows the impact of $\mathrm{Hg}$ (II) photoreduction (Kritee et al., 2007). Panel (d) shows sum of MMHg and $\mathrm{Hg}$ (II) photoreduction mechanisms. Locations for the Eq. Pac. and Olig. Atl. profiles are given in Fig. 4.

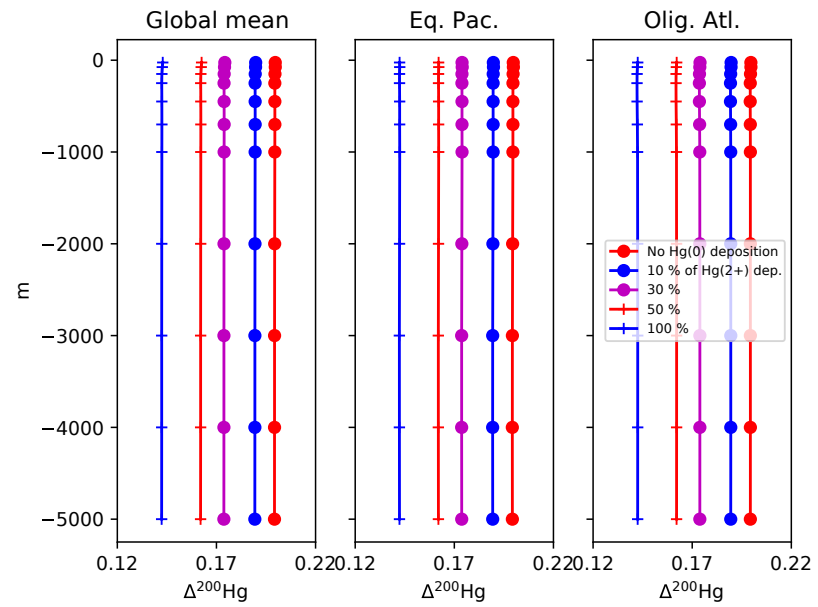

Figure 15. Profiles of the $\Delta^{200} \mathrm{Hg}$ isotopic composition of $\mathrm{Hg}$ (II) for different values of the dry deposition $(\mathrm{Hg}(0))$ flux. The rate of wet deposition is the same for all runs. Locations for the Eq. Pac. and Olig. Atl. profiles are given in Fig. 4.

in which $\mathrm{Hg}$ concentrations are not changing with time, the sinking flux of $\mathrm{Hg}$ through the ocean must be the same (on a horizontal average) at all depth levels.

A series of sensitivity runs with different $\mathrm{Hg}-\mathrm{P}$ sinking velocities shows that the observed present-day subsurface maximum in $\mathrm{Hg}(\mathrm{II})$ is a product of $\mathrm{Hg}$ sinking on particles and the anthropogenic increase in $\mathrm{Hg}$ deposition to the surface

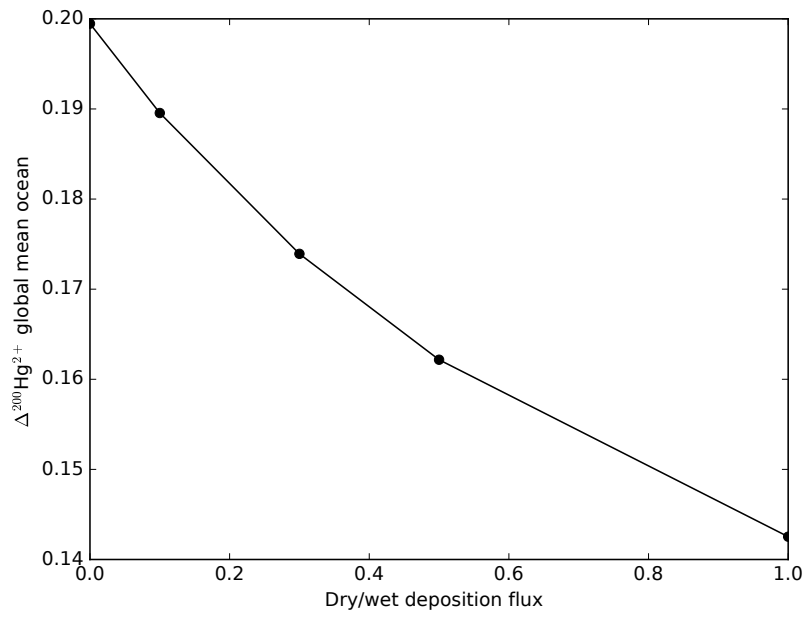

Figure 16. The $\Delta^{200} \mathrm{Hg}$ isotopic composition of the global mean ocean is a function of the ratio of wet to dry deposition fluxes.
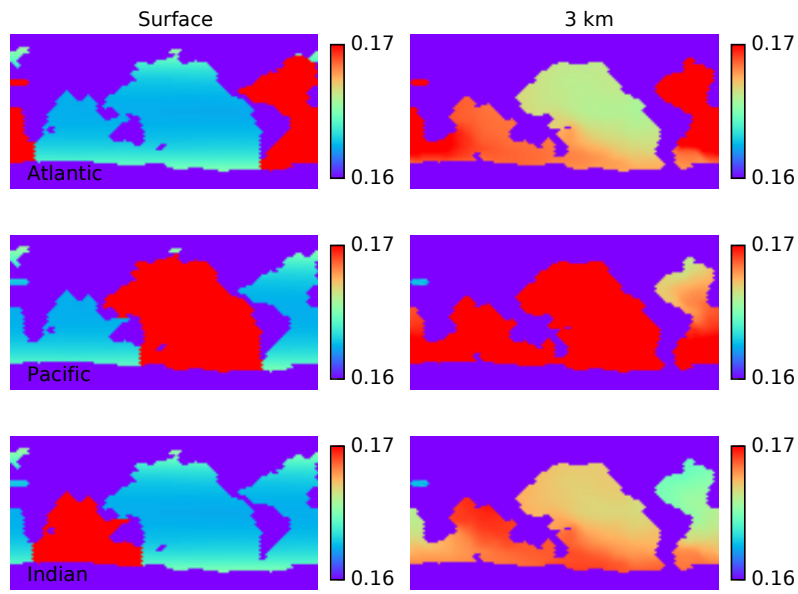

Figure 17. Maps of steady-state distribution of $\Delta^{200} \mathrm{Hg}$ (II) under conditions of a doubling of the $\mathrm{Hg}$ (II) deposition flux which is isolated to the Atlantic, Pacific, and Indian oceans. The isotopic signature at $3 \mathrm{~km}$ depth reflects differences in surface deposition.

ocean. Given the 4-fold enhanced $\mathrm{Hg}$ deposition flux since about 1850 (Streets et al., 2017), if there were no $\mathrm{Hg}$ sinking and subsurface release from particles, the highest $\mathrm{Hg}$ concentrations would be at the sea surface today. Anthropogenic $\mathrm{Hg}$ sinking on particles does not have a strong impact on the net uptake rate of anthropogenic $\mathrm{Hg}$ by the ocean, but if the enhanced rates of $\mathrm{Hg}$ deposition were suddenly to return to natural levels, a model with strong $\mathrm{Hg}$ sinking takes longer to shed its anthropogenic Hg burden. Since oceanic $\mathrm{Hg}$ evasion will be recycled and re-deposited, the ocean system seems poised to buffer the environmental $\mathrm{Hg}$ concentration for thousands of years.

We show the sensitivity of the steady-state (preanthropogenic, 1850) $\mathrm{Hg}$ species concentrations to eight kinetic rate constants in the aqueous $\mathrm{Hg}$ cycle. Allowing a reaction 
to proceed more quickly than a base case tends to result in more of the product and less of the reactant, but the magnitude of the change and the impact on the rest of the $\mathrm{Hg}$ species and the total $\mathrm{Hg}$ concentration vary widely between the various reactions. Changes to the budget of $\operatorname{Hg}(0)$, the evasion of which is the dominant loss mechanism for $\mathrm{Hg}$ in surface waters, have a strong impact on the rest of the $\mathrm{Hg}$ concentrations. Changes to reactions involved in the $\mathrm{MMHg}$ budget have a stronger impact on the $\mathrm{Hg}$ cycle than changes to DMHg sources or sinks, because MMHg is kinetically tied more closely to $\mathrm{Hg}(\mathrm{II})$.

Isotopic variations in $\mathrm{Hg}$ have multiple "dimensions" of fractionation, with mass-dependent fractionation produced by most processes, and several forms of mass-independent fractionation produced by photochemical reactions. The $\mathrm{Hg}$ cycle in the ocean is complex enough that a model is required to predict the "expression" of isotopic fractionations in processes, on the isotopic signatures of $\mathrm{Hg}$ species in the ocean, and on the distribution of variations in those signatures. There is wide variation in the expression of isotope fractionation effects in the isotopic composition of $\mathrm{Hg}$ standing stocks. In the model, surface-deep contrasts in $\delta^{202} \mathrm{Hg}$ (and $\Delta^{199} \mathrm{Hg}$ ) are due largely to fractionation in the rate of $\mathrm{Hg}$ (II) biological+photochemical reduction. This mechanism also generates a contrast between Atlantic and Pacific deep isotopic compositions. The photochemical reduction of MMHg generates a dramatic contrast between the $\Delta^{199} \mathrm{Hg}$ of MMHg and $\mathrm{Hg}(\mathrm{II})$ in the surface ocean, consistent with isotopic measurements of fish (Blum et al., 2013). Multiple mechanisms produced patterns in sea surface $\delta^{202} \mathrm{Hg}$ signatures, some creating high $\delta^{202} \mathrm{Hg}$ excursions in productive areas and some producing low $\delta^{202} \mathrm{Hg}$ excursions. These mechanisms are as follows for high $\delta^{202} \mathrm{Hg}$ excursions in, for example, the equatorial Pacific: $\mathrm{MMHg}$ photoreduction, biological MMHg production, and $\mathrm{Hg}(\mathrm{II})$ adsorption. For low $\delta^{202} \mathrm{Hg}$ excursions, they are as follows: $\mathrm{Hg}(0)$ evasion, $\mathrm{Hg}(\mathrm{II})$ reduction, biological MMHg production, $\mathrm{MMHg}$ biodegradation, and $\mathrm{Hg}(\mathrm{II})$ adsorption. The $\Delta^{199} \mathrm{Hg}$ system in the model is entirely driven by photochemical reactions ( $\mathrm{Hg}$ (II) and $\mathrm{MMHg}$ photoreduction). In reality there may be variations in source input, but the rates and isotopic signatures of $\mathrm{Hg}$ deposition are spatially uniform in the model. Both photochemical mechanisms produce heterogeneity at the sea surface that is driven by differences in particle export. The only depth contrast in $\Delta^{199} \mathrm{Hg}$ predicted by the model is for $\Delta^{199} \mathrm{Hg}$ of $\mathrm{MMHg}$ due to MMHg photoreduction. The $\Delta^{200} \mathrm{Hg}$ of the ocean on global average in the model reflects the balance of wet vs. dry deposition of $\mathrm{Hg}$ ( $\mathrm{Hg}$ (II) vs. $\operatorname{Hg}(0)$ ), and regional variations in those rain rates at the sea surface in the model may be weakly represented in the isotopic composition of the deep ocean basins.
Code availability. Fortran source code is available in a repository at https://doi.org/10.6082/ngqr-zf89 (Archer and Blum, 2018), which also contains selected model output.

Supplement. The supplement related to this article is available online at: https://doi.org/10.5194/bg-15-6297-2018-supplement.

Author contributions. DEA did the coding and plotting, both authors designed the study, analyzed the results, and wrote the paper.

Competing interests. The authors declare that they have no conflict of interest.

Special issue statement. This article is part of the special issue "Progress in quantifying ocean biogeochemistry - in honour of Ernst Maier-Reimer". It is not associated with a conference.

Acknowledgements. This work stands on the shoulders of Ernst Maier-Reimer who created the HAMOCC model. It also benefitted immensely from the constructive criticism of Jeroen Sonke and another anonymous reviewer.

Edited by: Christoph Heinze

Reviewed by: Jeroen Sonke and one anonymous referee

\section{References}

Amos, H. M., Jacob, D. J., Streets, D. G., and Sunderland, E. M.: Legacy impacts of all-time anthropogenic emissions on the global mercury cycle, Global Biogeochem. Cy., 27, 410-421, https://doi.org/10.1002/gbc.20040, 2013.

Anderson, R. F., Cheng, H., Edwards, R. L., Fleisher, M. Q., Hayes, C. T., Huang, K. F., Kadko, D., Lam, P. J., Landing, W. M., Lao, Y., Lu, Y., Measures, C. I., Moran, S. B., Morton, P. L., Ohnemus, D. C., Robinson, L. F., and Shelley, R. U.: How well can we quantify dust deposition to the ocean?, Philos. T. Roy. Soc. A, 374, 20150285, https://doi.org/10.1098/rsta.2015.0285, 2016.

Archer, D. E. and Blum, J.: A model of mercury cycling and isotopic fractionation in the ocean, https://doi.org/10.6082/ngqrzf89, 2018.

Archer, D. E., Eby, M., Brovkin, V., Ridgewell, A. J., Cao, L., Mikolajewicz, U., Caldeira, K., Matsueda, H., Munhoven, G., Montenegro, A., and Tokos, K.: Atmospheric lifetime of fossil fuel carbon dioxide, Ann. Rev. Earth Planet Sci., 37, 117-134, 2009.

Balogh, S. J., Tsui, M. T. K., Blum, J. D., Matsuyama, A., Woerndle, G. E., Yano, S., and Tada, A.: Tracking the Fate of Mercury in the Fish and Bottom Sediments of Minamata Bay, Japan, Using Stable Mercury Isotopes, Environ. Sci. Technol., 49, 5399_ 5406, https://doi.org/10.1021/acs.est.5b00631, 2015.

Bergquist, B. A. and Blum, J. D.: Mass-dependent and -independent fractionation of $\mathrm{Hg}$ isotopes by photore- 
duction in aquatic systems, Science, 318, 417-420, https://doi.org/10.1126/science.1148050, 2007.

Bergquist, R. A. and Blum, J. D.: The Odds and Evens of Mercury Isotopes: Applications of Mass-Dependent and Mass-Independent Isotope Fractionation, Elements, 5, 353-357, https://doi.org/10.2113/gselements.5.6.353, 2009.

Biswas, A., Blum, J. D., and Keeler, G. J.: Mercury storage in surface soils in a central Washington forest and estimated release during the 2001 Rex Creek Fire, Sci. Total Environ., 404, 129138, https://doi.org/10.1016/j.scitotenv.2008.05.043, 2008.

Blum, J. D.: Mesmerized by mercury, Nature Chemistry, 5, 10661066, https://doi.org/10.1038/nchem.1803, 2013.

Blum, J. D., Popp, B. N., Drazen, J. C., Choy, C. A., and Johnson, M. W.: Methylmercury production below the mixed layer in the North Pacific Ocean, Nature Geosci., 6, 879-884, https://doi.org/10.1038/ngeo1918, 2013.

Blum, J. D., Sherman, L. S., and Johnson, M. W.: Mercury Isotopes in Earth and Environmental Sciences, in: Annu. Rev. Earth Planet. Sci., Vol 42, edited by: Jeanloz, R., Annu. Rev. Earth Planet. Sci., 42, 249-269, 2014.

Bowman, K. L., Hammerschmidt, C. R., Lamborg, C. H., and Swarr, G.: Mercury in the North Atlantic Ocean: The US GEOTRACES zonal and meridional sections, Deep-Sea Res. Pt. II, 116, 251-261, https://doi.org/10.1016/j.dsr2.2014.07.004, 2015.

Bowman, K. L., Hammerschmidt, C. R., Lamborg, C. H., Swarr, G. J., and Agather, A. M.: Distribution of mercury species across a zonal section of the eastern tropical South Pacific Ocean (US GEOTRACES GP16), Mar. Chem., 186, 156-166, https://doi.org/10.1016/j.marchem.2016.09.005, 2016.

Broecker, W. S. and Peng, T.-H.: Gas exchange rate between sea and air, Tellus, 26, 21-35, 1974.

Buchachenko, A. L.: Magnetic isotope effect: Nuclear spin control of chemical reactions, J. Phys. Chem. A, 105, 9995-10011, https://doi.org/10.1021/jp011261d, 2001.

Chakraborty, P., Mason, R. P., Jayachandran, S., Vudamala, K., Armoury, K., Sarkar, A., Chakraborty, S., Bardhan, P., and Naik, R.: Effects of bottom water oxygen concentrations on mercury distribution and speciation in sediments below the oxygen minimum zone of the Arabian Sea, Mar. Chem., 186, 24-32, https://doi.org/10.1016/j.marchem.2016.07.005, 2016.

Chandan, P., Ghosh, S., and Bergquist, B. A.: Mercury Isotope Fractionation during Aqueous Photoreduction of Monomethylmercury in the Presence of Dissolved Organic Matter, Environ. Sci. Technol., 49, 259-267, https://doi.org/10.1021/es5034553, 2015.

Chen, C. Y., Driscoll, C. T., Lambert, K. F., Mason, R. P., and Sunderland, E. M.: Connecting mercury science to policy: from sources to seafood, Rev. Environ. Health, 31, 17-20, https://doi.org/10.1515/reveh-2015-0044, 2016.

Clarkson, T. W. and Magos, L.: The toxicology of mercury and its chemical compounds, Critical Reviews in Toxicology, 36, 609662, https://doi.org/10.1080/10408440600845619, 2006.

Cossa, D., Cotte-Krief, M. H., Mason, R. P., and BretaudeauSanjuan, J.: Total mercury in the water column near the shelf edge of the European continental margin, Mar. Chem., 90, 2129, https://doi.org/10.1016/j.marchem.2004.02.019, 2004.

Cossa, D., Heimburger, L. E., Lannuzel, D., Rintoul, S. R., Butler, E. C. V., Bowie, A. R., Averty, B., Watson, R. J., and Remenyi, T.: Mercury in the Southern Ocean, Geochim. Cosmochim. Acta, 75, 4037-4052, https://doi.org/10.1016/j.gca.2011.05.001, 2011.
Demers, J. D., Sherman, L. S., Blum, J. D., Marsik, F. J., and Dvonch, J. T.: Coupling atmospheric mercury isotope ratios and meteorology to identify sources of mercury impacting a coastal urban-industrial region near Pensacola, Florida, USA, Global Biogeochem. Cy., 29, 1689-1705, https://doi.org/10.1002/2015gb005146, 2015.

Donovan, P. M., Blum, J. D., Yee, D., Gehrke, G. E., and Singer, M. B.: An isotopic record of mercury in San Francisco Bay sediment, Chem. Geol., 349, 87-98, https://doi.org/10.1016/j.chemgeo.2013.04.017, 2013.

Donovan, P. M., Blum, J. D., Demers, J. D., Gu, B. H., Brooks, S. C., and Peryam, J.: Identification of Multiple Mercury Sources to Stream Sediments near Oak Ridge, TN, USA, Environ. Sci. Technol., 48, 3666-3674, https://doi.org/10.1021/es4046549, 2014.

Driscoll, C. T., Mason, R. P., Chan, H. M., Jacob, D. J., and Pirrone, N.: Mercury as a Global Pollutant: Sources, Pathways, and Effects, Environ. Sci. Technol., 47, 4967-4983, https://doi.org/10.1021/es305071v, 2013.

Fitzgerald, W. F., Lamborg, C. H., and Hammerschmidt, C. R.: Marine biogeochemical cycling of mercury, Chem. Rev., 107, 641662, https://doi.org/10.1021/cr050353m, 2007.

Foucher, D., Hintelmann, H., Al, T. A., and MacQuarrie, K. T.: Mercury isotope fractionation in waters and sediments of the Murray Brook mine watershed (New Brunswick, Canada): tracing mercury contamination and transformation, Chem. Geol., 336, 8795, 2013.

Gebbie, G. and Huybers, P.: The Mean Age of Ocean Waters Inferred from Radiocarbon Observations: Sensitivity to Surface Sources and Accounting for Mixing Histories, J. Phys. Oceanogr., 42, 291-305, https://doi.org/10.1175/jpo-d-11-043.1, 2012.

Gehrke, G. E., Blum, J. D., Slotton, D. G., and Greenfield, B. K.: Mercury Isotopes Link Mercury in San Francisco Bay Forage Fish to Surface Sediments, Environ. Sci. Technol., 45, 1264 1270, https://doi.org/10.1021/es103053y, 2011.

Gratz, L. E., Keeler, G. J., Blum, J. D., and Sherman, L. S.: Isotopic Composition and Fractionation of Mercury in Great Lakes Precipitation and Ambient Air, Environ. Sci. Technol., 44, 77647770, https://doi.org/10.1021/es100383w, 2010.

Hammerschmidt, C. R. and Bowman, K. L.: Vertical methylmercury distribution in the subtropical North Pacific Ocean, Mar. Chem., 132, 77-82, https://doi.org/10.1016/j.marchem.2012.02.005, 2012.

Han, S. H., Gill, G. A., Lehman, R. D., and Choe, K. Y.: Complexation of mercury by dissolved organic matter in surface waters of Galveston Bay, Texas, Mar. Chem., 98, 156-166, https://doi.org/10.1016/j.marchem.2005.07.004, 2006.

Hollweg, T. A., Gilmour, C. C., and Mason, R. P.: Mercury and methylmercury cycling in sediments of the mid-Atlantic continental shelf and slope, Limnol. Oceanogr., 55, 2703-2722, https://doi.org/10.4319/lo.2010.55.6.2703, 2010.

Horowitz, H. M., Jacob, D. J., Amos, H. M., Streets, D. G., and Sunderland, E. M.: Historical Mercury Releases from Commercial Products: Global Environmental Implications, Environ. Sci. Technol., 48, 10242-10250, https://doi.org/10.1021/es501337j, 2014. 
Jiskra, M. W. J., Bourdon, B., and Kretzschmar, R.: Solution speciation controls mercury isotope fractionation of $\mathrm{Hg}(\mathrm{II})$ sorption to goethite, Environ. Sci. Technol., 46, 6654-6662, 2012.

Jonsson, S., Mazrui, N. M., and Mason, R. P.: Dimethylmercury Formation Mediated by Inorganic and Organic Reduced Sulfur Surfaces, Scientific Reports, 6, 27958, https://doi.org/10.1038/srep27958, 2016.

Krabbenhoft, D. P. and Sunderland, E. M.: Global Change and Mercury, Science, 341, 1457-1458, https://doi.org/10.1126/science.1242838, 2013.

Kritee, K., Blum, J. D., Johnson, M. W., Bergquist, B. A., and Barkay, T.: Mercury stable isotope fractionation during reduction of $\mathrm{Hg}(\mathrm{II})$ to $\mathrm{Hg}(0)$ by mercury resistant microorganisms, Environ. Sci. Technol., 41, 1889-1895, https://doi.org/10.1021/es062019t, 2007.

Kwon, S. Y., Blum, J. D., Chirby, M. A., and Chesney, E. J.: Application of mercury isotopes for tracing trophic transfer and internal distribution of mercury in marine fish feeding experiments, Environ. Toxicol. Chem., 32, 2322-2330, https://doi.org/10.1002/etc.2313, 2013.

Kwon, S. Y., Blum, J. D., Chen, C. Y., Meattey, D. E., and Mason, R. P.: Mercury Isotope Study of Sources and Exposure Pathways of Methylmercury in Estuarine Food Webs in the Northeastern US, Environ. Sci. Technol., 48, 10089-10097, https://doi.org/10.1021/es5020554, 2014.

Lamborg, C., Bowman, K., Hammerschmidt, C., Gilmour, C., Munson, K., Selin, N., and Tseng, C. M.: MERCURY in the Anthropocene Ocean, Oceanography, 27, 76-87, https://doi.org/10.5670/oceanog.2014.11, 2014.

Lamborg, C. H., Hammerschmidt, C. R., Gill, G. A., Mason, R. P., and Gichuki, S.: An intercomparison of procedures for the determination of total mercury in seawater and recommendations regarding mercury speciation during GEOTRACES cruises, Limnol. Oceanogr--Methods, 10, 90-100, https://doi.org/10.4319/lom.2012.10.90, 2012.

Lamborg, C. H., Hammerschmidt, C. R., and Bowman, K. L.: An examination of the role of particles in oceanic mercury cycling, Philos. T. Roy. Soc. A, 374, 20150297, https://doi.org/10.1098/rsta.2015.0297, 2016.

Laurier, F. J. G., Mason, R. P., Gill, G. A., and Whalin, L.: Mercury distributions in the North Pacific Ocean - 20 years of observations, Mar. Chem., 90, 3-19, https://doi.org/10.1016/j.marchem.2004.02.025, 2004.

Lehnherr, I.: Methylmercury biogeochemistry: a review with special reference to Arctic aquatic ecosystems, Environ. Rev., 22, 229-243, https://doi.org/10.1139/er-2013-0059, 2014.

Lehnherr, I., St. Louis, V. L., Hintelmann, H., and Kirk, J. L.: Methylation of inorganic mercury in polar marine waters, Nature Geosci., 4, 298-302, https://doi.org/10.1038/ngeo1134, 2011.

Li, M. L., Sherman, L. S., Blum, J. D., Grandjean, P., Mikkelsen, B., Weihe, P., Sunderland, E. M., and Shine, J. P.: Assessing Sources of Human Methylmercury Exposure Using Stable Mercury Isotopes, Environ. Sci. Technol., 48, 8800-8806, https://doi.org/10.1021/es500340r, 2014.

Maier-Reimer, E.: Towards a global ocean carbon model, Prog. Biometeorol., 3, 295-310, 1984.

Maier-Reimer, E.: Geochemical cycles in an ocean general circulation model. Preindusrial tracer distributions, Global Biogeochem. Сy., 7, 645-678, 1993.
Maier-Reimer, E. and Bacastow, R.: Modelling of geochemical tracers in the ocean, in: Climate-Ocean Interaction, edited by: Schlesinger, M. E., Kluwer, Netherlands, 233-267, 1990.

Maier-Reimer, E. and Hasselmann, K.: Transport and storage of $\mathrm{CO}_{2}$ in the ocean - an inorganic ocean-circulation carbon cycle model, Clim. Dynam., 2, 63-90, 1987.

Mason, R. P., Rolfhus, K. R., and Fitzgerald, W. F.: Mercury in the North Atlantic, Mar. Chem., 61, 37-53, https://doi.org/10.1016/s0304-4203(98)00006-1, 1998.

Mason, R. P., Lawson, N. M., and Sheu, G. R.: Mercury in the Atlantic Ocean: factors controlling air-sea exchange of mercury and its distribution in the upper waters, Deep-Sea Res. Pt. II, 48, 2829-2853, https://doi.org/10.1016/s0967-0645(01)00020$0,2001$.

Mason, R. P., Choi, A. L., Fitzgerald, W. F., Hammerschmidt, C. R., Lamborg, C. H., Soerensen, A. L., and Sunderland, E. M.: Mercury biogeochemical cycling in the ocean and policy implications, Environ. Res., 119, 101-117, https://doi.org/10.1016/j.envres.2012.03.013, 2012.

Motta, L. C., Blum, J., Johnson, M. W., Washburn, S. J., Popp, B. N., Close, H., Umhau, B., Benitez-Nelson, C., and Hannides, C.: $\mathrm{Hg}$ cycling in the North Pacific Subtropical Gyre as revealed by Hg isotopes, Global Biogeochem. Cy., in review, 2018.

Munson, K. M., Lamborg, C. H., Swarr, G. J., and Saito, M. A.: Mercury species concentrations and fluxes in the Central Tropical Pacific Ocean, Global Biogeochem. Cy., 29, 656-676, https://doi.org/10.1002/2015gb005120, 2015.

Obrist, D., Agnan, Y., Jiskra, M., Olson, C. L., Colegrove, D. P., Hueber, J., Moore, C. W., Sonke, J. E., and Helmig, D.: Tundra uptake of atmospheric elemental mercury drives Arctic mercury pollution, Nature, 547, 201-204, https://doi.org/10.1038/nature22997, 2017.

Obrist, D., Kirk, J. L., Zhang, L., Sunderland, E. M., Jiskra, M., and Selin, N. E.: A review of global environmental mercury processes in response to human and natural perturbations: Changes of emissions, climate, and land use, Ambio, 47, 116140, https://doi.org/10.1007/s13280-017-1004-9, 2018.

Ortiz, V. L., Mason, R. P., and Ward, J. E.: An examination of the factors influencing mercury and methylmercury particulate distributions, methylation and demethylation rates in laboratory-generated marine snow, Mar. Chem., 177, 753-762, https://doi.org/10.1016/j.marchem.2015.07.006, 2015.

Ray, E. A., Moore, F. L., Elkins, J. W., Rosenlof, K. H., Laube, J. C., Rockmann, T., Marsh, D. R., and Andrews, A. E.: Quantification of the SF6 lifetime based on mesospheric loss measured in the stratospheric polar vortex, J. Geophys. Res.-Atmos., 122, 46264638, https://doi.org/10.1002/2016jd026198, 2017.

Rodriguez-Gonzalez, P., Epov, V. N., Bridou, R., Tessier, E., Guyoneaud, R., Monperrus, M., and Amouroux, D.: Species-Specific Stable Isotope Fractionation of Mercury during $\mathrm{Hg}$ (II) Methylation by an Anaerobic Bacteria (Desulfobulbus propionicus) under Dark Conditions, Environ. Sci. Technol., 43, 9183-9188, https://doi.org/10.1021/es902206j, 2009.

Rose, C. H., Ghosh, S., Blum, J. D., and Bergquist, B. A.: Effects of ultraviolet radiation on mercury isotope fractionation during photo-reduction for inorganic and organic mercury species, Chem. Geol., 405, 102-111, https://doi.org/10.1016/j.chemgeo.2015.02.025, 2015. 
Schartup, A. T., Mason, R. P., Balcom, P. H., Hollweg, T. A., and Chen, C. Y.: Methylmercury Production in Estuarine Sediments: Role of Organic Matter, Environ. Sci. Technol., 47, 695-700, https://doi.org/10.1021/es302566w, 2013.

Schartup, A. T., Ndu, U., Balcom, P. H., Mason, R. P., and Sunderland, E. M.: Contrasting Effects of Marine and Terrestrially Derived Dissolved Organic Matter on Mercury Speciation and Bioavailability in Seawater, Environ. Sci. Technol., 49, 59655972, https://doi.org/10.1021/es506274x, 2015.

Schartup, A. T., Qureshi, A., Dassuncao, C., Thackray, C. P., Harding, G., and Sunderland, E. M.: A Model for Methylmercury Uptake and Trophic Transfer by Marine Plankton, Environ. Sci. Technol., 52, 654-662, https://doi.org/10.1021/acs.est.7b03821, 2018.

Schauble, E. A.: Role of nuclear volume in driving equilibrium stable isotope fractionation of mercury, thallium, and other very heavy elements, Geochim. Cosmochim. Acta, 71, 2170-2189, https://doi.org/10.1016/j.gca.2007.02.004, 2007.

Schuster, P. F., Schaefer, K. M., Aiken, G. R., Antweiler, R. C., Dewild, J. F., Gryziec, J. D., Gusmeroli, A., Hugelius, G., Jafarov, E., Krabbenhoft, D. P., Liu, L., Herman-Mercer, N., Mu, C., Roth, D. A., Schaefer, T., Striegl, R. G., Wickland, K. P., and Zhang, T.: Permafrost Stores a Globally Significant Amount of Mercury, Geophys. Res. Lett., 45, 1463-1471, https://doi.org/10.1002/2017GL075571, 2018.

Semeniuk, K. and Dastoor, A.: Development of a global ocean mercury model with a methylation cycle: Outstanding issues, Global Biogeochem. Cy., 31, 400-433, https://doi.org/10.1002/2016gb005452, 2017.

Sherman, L. S., Blum, J. D., Franzblau, A., and Basu, N.: New Insight into Biomarkers of Human Mercury Exposure Using Naturally Occurring Mercury Stable Isotopes, Environ. Sci. Technol., 47, 3403-3409, https://doi.org/10.1021/es305250z, 2013.

Sherman, L. S., Blum, J. D., Basu, N., Rajaee, M., Evers, D. C., Buck, D. G., Petrlik, J., and DiGangi, J.: Assessment of mercury exposure among small-scale gold miners using mercury stable isotopes, Environ. Res., 137, 226-234, https://doi.org/10.1016/j.envres.2014.12.021, 2015.

Smith-Downey, N. V., Sunderland, E. M., and Jacob, D. J.: Anthropogenic impacts on global storage and emissions of mercury from terrestrial soils: Insights from a new global model, J. Geophys. Res.-Biogeosci., 115, G03008, https://doi.org/10.1029/2009jg001124, 2010.

Soerensen, A. L., Sunderland, E. M., Holmes, C. D., Jacob, D. J., Yantosca, R. M., Skov, H., Christensen, J. H., Strode, S. A., and Mason, R. P.: An Improved Global Model for Air-Sea Exchange of Mercury: High Concentrations over the North Atlantic, Environ. Sci. Technol., 44, 8574-8580, https://doi.org/10.1021/es102032g, 2010.

Sonke, J. E., Schafer, J., Chmeleff, J., Audry, S., Blanc, G., and Dupre, B.: Sedimentary mercury stable isotope records of atmospheric and riverine pollution from two major European heavy metal refineries, Chem. Geol., 279, 90-100, 2010.

Streets, D. G., Devane, M. K., Lu, Z. F., Bond, T. C., Sunderland, E. M., and Jacob, D. J.: All-Time Releases of Mercury to the Atmosphere from Human Activities, Environ. Sci. Technol., 45, 10485-10491, https://doi.org/10.1021/es202765m, 2011.
Streets, D. G., Horowitz, H. M., Jacob, D., Lu, Z. F., Levin, L., ter Schure, A. F. H., and Sunderland, E. M.: Total Mercury Released to the Environment by Human Activities, Environ. Sci. Technol., 51, 5969-5977, https://doi.org/10.1021/acs.est.7b00451, 2017.

Strok, M., Baya, P. A., and Hintelmann, H.: The mercury isotope composition of Arctic coastal seawater, Comptes Rendus Geoscience, 347, 368-376, https://doi.org/10.1016/j.crte.2015.04.001, 2015.

Sun, R. Y., Streets, D. G., Horowitz, H. M., Amos, H. M., Liu, G. J., Perrot, V., Toutain, J. P., Hintelmann, H., Sunderland, E. M., and Sonke, J. E.: Historical (1850-2010) mercury stable isotope inventory from anthropogenic sources to the atmosphere, Elementa-Science of the Anthropocene, 4, 1-15, https://doi.org/10.12952/journal.elementa.000091, 2016.

Tsui, M. T. K., Blum, J. D., Finlay, J. C., Balogh, S. J., Nollet, Y. H., Palen, W. J., and Power, M. E.: Variation in Terrestrial and Aquatic Sources of Methylmercury in Stream Predators as Revealed by Stable Mercury Isotopes, Environ. Sci. Technol., 48, 10128-10135, https://doi.org/10.1021/es500517s, 2014.

Turetsky, M. R., Harden, J. W., Friedli, H. R., Flannigan, M., Payne, N., Crock, J., and Radke, L.: Wildfires threaten mercury stocks in northern soils, Geophys. Res. Lett., 33, L16403, https://doi.org/10.1029/2005GL025595, 2006.

Wiederhold, J. G., Cramer, C. J., Daniel, K., Infante, I., Bourdon, B., and Kretzschmar, R.: Equilibrium Mercury Isotope Fractionation between Dissolved $\mathrm{Hg}$ (II) Species and Thiol-Bound Hg, Environ. Sci. Technol., 44, 4191-4197, https://doi.org/10.1021/es100205t, 2010.

Yang, L. and Sturgeon, R.: Isotopic fractionation of mercury induced by reduction and ethylation, Anal. Bioanal. Chem., 393, 377-385, https://doi.org/10.1007/s00216-008-2348-6, 2009.

Yin, R., Feng, X. B., Wang, J., Bao, Z., Yu, B., and Chen, J.: Mercury isotope variations between bioavailable mercury fractions and total mercury in mercury contaminated soil in Wanshan mercury mine, SW China, Chem Geol., 336, 72-79, 2013.

Zhang, Y. X., Jaegle, L., and Thompson, L.: Natural biogeochemical cycle of mercury in a global three-dimensional ocean tracer model, Glob. Biogeochem. Cy., 28, 553-570, https://doi.org/10.1002/2014GB004814, 2014a.

Zhang, Y. X., Jaegle, L., Thompson, L., and Streets, D. G.: Six centuries of changing oceanic mercury, Global Biogeochem. Cy., 28, 1251-1261, https://doi.org/10.1002/2014gb004939, 2014b.

Zheng, W. and Hintelmann, H.: Nuclear Field Shift Effect in Isotope Fractionation of Mercury during Abiotic Reduction in the Absence of Light, J. Phys. Chem. A, 114, 4238-4245, https://doi.org/10.1021/jp910353y, 2010.

Zheng, W., Obrist, D., Weis, D., and Bergquist, B. A.: Mercury isotope compositions across North American forests, Global Biogeochem. Cy., 30, 1475-1492, https://doi.org/10.1002/2015gb005323, 2016. 